\title{
Copper-based oxygen carriers supported with alumina/lime for the chemical looping conversion of gaseous fuels
}

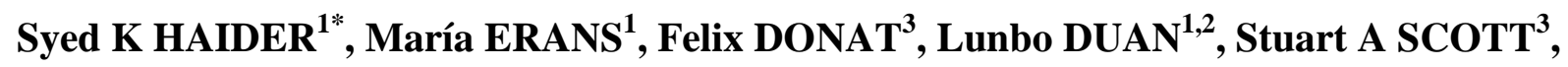 \\ Vasilije MANOVIC ${ }^{1}$, Edward J ANTHONY ${ }^{1}$ \\ ${ }^{1}$ Combustion and CCS Centre, Cranfield University, Bedfordshire, MK43 OAL, UK \\ ${ }^{2}$ Key Laboratory of Energy Thermal Conversion and Control, Ministry of Education, School of \\ Energy and Environment, Southeast University, Nanjing, 210096, China \\ ${ }^{3}$ Department of Engineering, University of Cambridge, Trumpington Street, Cambridge, UK \\ *Corresponding author, haidersyedkumail@gmail.com
}

\begin{abstract}
Copper (II) oxide in varying ratios was combined with either an alumina-based cement (A1300), or $\mathrm{CaO}$ derived from limestone as support material in a mechanical pelletiser. This production method was used to investigate its influence on possible mechanical and chemical improvements for oxygen carriers in chemical looping processes. These materials were tested in a lab-scale fluidised bed with $\mathrm{CO}$ or $\mathrm{CH}_{4}$ as a reducing gas at $950{ }^{\circ} \mathrm{C}$. As expected, the oxygen carriers containing a greater ratio of support material exhibited an enhanced crushing strength. Oxygen carriers comprised of a 1:3 ratio of support material to active $\mathrm{CuO}$ exhibited increased crushing strength by a minimum of $280 \%$ compared to pure $\mathrm{CuO}$ pellets. All oxygen carriers exhibited a high $\mathrm{CO}$ conversion yield and were fully reducible from $\mathrm{CuO}$ to $\mathrm{Cu}$. For the initial redox cycle, A1300-supported oxygen carriers showed the highest fuel and oxygen carrier conversion. The general trend observed was a decline in conversion with an increasing number of redox cycles. In the case of $\mathrm{CaO}$-supported oxygen carriers, all but one of the oxygen carriers suffered agglomeration. The agglomeration was more severe in carriers with higher ratios of $\mathrm{CuO}$. Oxygen carrier $\mathrm{Cu} 25 \mathrm{Al} 75$ (75\% wt. aluminate cement and $25 \%$ wt. $\mathrm{CuO}$ ), which did not suffer from agglomeration, showed the highest attrition with a loss of approximately $8 \%$ of its initial mass over 25 redox cycles. The reducibility of the oxygen carriers was limited with $\mathrm{CH}_{4}$ in comparison to $\mathrm{CO} . \mathrm{CH}_{4}$ conversion yielded $15-25 \%$ and $50 \%$ for $\mathrm{Cu} 25 \mathrm{Ca} 75$ (25\% wt. $\mathrm{CuO}$ and $75 \%$ wt. $\mathrm{CaO}$ ) and $\mathrm{Cu} 25 \mathrm{~A} 175$, respectively. Cu25Ca75 demonstrated improved conversion, whereas $\mathrm{Cu} 25 \mathrm{Al} 75$ exhibited a trending decrease in conversion with increasing redox cycles.
\end{abstract}




\section{Introduction}

Chemical looping combustion (CLC) is a highly efficient fuel-processing technology with inherent $\mathrm{CO}_{2}$ separation. The resulting flue gas from the process is rich in $\mathrm{CO}_{2}$, which can be utilised or compressed and stored. The technology's greatest advantage is its ability to separate oxygen from combustion air and utilise it directly in the conversion of a carbonaceous fuel. This process can avoid the otherwise necessary post-combustion flue gas treatment and energy penalty associated with conventional combustion taking place in air [1]. CLC systems are typically comprised of two interconnected fluidised bed reactors, denoted as a fuel reactor and air reactor with a recirculating oxygen carrier. This oxygen carrier (typically a transition metal oxide) allows the conversion of the carbonaceous fuel, be it gas [2], liquid [3] or a solid fuel [4]. A simplified CLC process is shown in Figure 1. The two fluid beds are abbreviated as AR for the air reactor and FR for the fuel reactor. In the FR the oxidised oxygen carrier provides the necessary oxygen for the fuel conversion, allowing for combustion products to be formed as the flue gas. The now reduced oxygen carrier is transferred to the AR where it is then re-oxidised, allowing the cyclic process to continue [5].

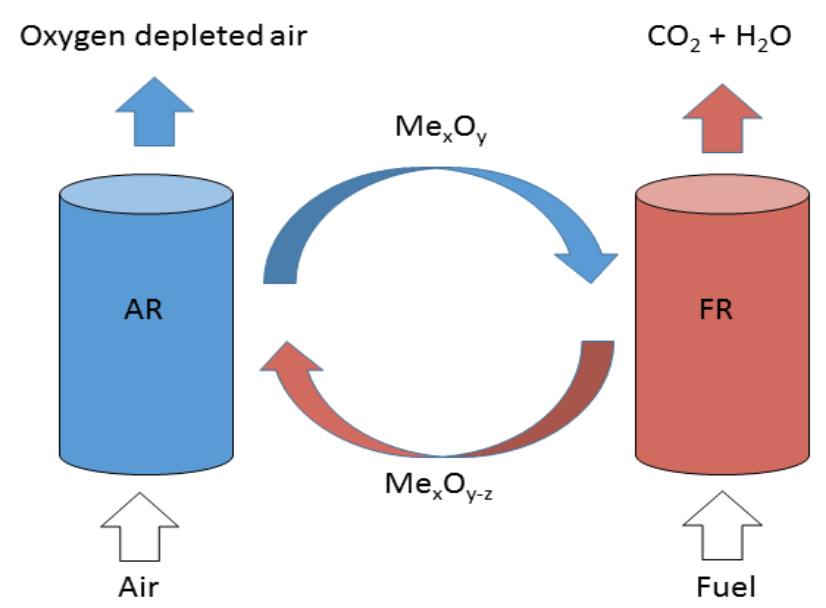

Figure 1: Simplified CLC process, adapted from [5]

With the maturity of fluidised bed technology established as an important means of fuel processing, CLC requires a suitable and stable oxygen carrier for the process to be employed at larger scales. Oxygen carrier research has been prolific since 2001 with many candidate materials tested [6].

Copper-based materials have been studied as potential oxygen carriers for the chemical looping process in great detail [7-12]. Copper-based systems have favourable redox characteristics, where both the oxidation and reduction reactions are exothermic; they also possess a high oxygen transfer capacity. Furthermore, copper systems can decompose to a lower metal oxidation state liberating gaseous oxygen at low oxygen potentials and is known as the chemical looping with oxygen uncoupling (CLOU) process [13]. The gaseous oxygen released in the CLOU process can greatly enhance the oxidation of char by avoiding the 
necessity of the char to be gasified into a synthesis gas for combustion in the conventional CLC process.

Examples of the benefits provided by the CLOU properties of a copper-based system are demonstrated by the fact that the conversion rate of a solid fuel, for example petroleum coke, can be increased by a factor of 80 times [14] compared to conventional solid fuel CLC. This faster rate of conversion can reduce the requirement of the solids inventory and total reactor volume for a given fuel feeding rate and, hence, reduce the associated capital and operational costs of a CLC process [9]. It has been calculated that the amount of oxygen carrier per $\mathrm{MW}_{\text {th }}$ of input fuel could be reduced to approximately $135 \mathrm{~kg}$ using $\mathrm{CuO}$. By contrast, one would require approximately $1200 \mathrm{~kg}$ per $\mathrm{MW}_{\text {th }}$ of fuel input for $\mathrm{Fe}_{2} \mathrm{O}_{3}$ operating in conventional CLC process [15]. Like all oxygen carriers in the fluidised bed process, these carriers are subjected to mechanical and chemical reaction stresses. In terms of CuO-based oxygen carriers, the copper oxide component is far more costly than some alternatives, for example, they are likely to cost about 10 times more than a comparable iron oxide carrier [6]. It is, therefore, imperative that the material inventory losses associated with attrition should be minimised. Attrition resulting from both mechanical and chemical reaction stresses can be significantly reduced by the appropriate choice of a support material for the active phase, as well as by the choice of the method of preparation of the oxygen carrier. However, all methods of oxygen carrier preparation must be scalable in order to produce the quantities required in full-scale operation. Also, the material utilised as a support should be of relatively low cost to ensure the overall cost of the produced oxygen carrier is minimised.

This investigation consisted of an experimental study, in which $\mathrm{CuO}$ as the active phase was produced as an oxygen carrier in varying ratios with a low-cost support material, consisting of $\mathrm{CaO}$ derived from a natural limestone, or alumina-based cement. The oxygen carriers produced were characterised through means of X-ray diffraction spectroscopy (XRD), scanning electron microscopy (SEM) with energy-dispersive X-ray spectroscopy (EDX), crushing strength and measurement of bulk density. Their assessment through these characterisation techniques helped determine their suitability in a CLC process. The oxygen carriers were then investigated for their efficacy for gaseous fuel conversion. This was assessed in a cyclic redox investigation with $\mathrm{CO}$ as a reducing gas in a lab-scale fluidised bed reactor. The oxygen carriers showing better suitability were finally further investigated for their reactivity and conversion of $\mathrm{CH}_{4}$.

\section{Experimental}

\subsection{Materials}

The support material for the oxygen carriers produced was $\mathrm{CaO}$, which was obtained from the calcination of limestone from Longcliffe (UK), or an alumina-based cement, traded as 'Alpha-bond 300', sourced from Almatis GmbH (Germany) and referred to as Al300. The $\mathrm{CuO}$ was obtained from Johnson Matthey (UK). The produced series of oxygen carriers had varying weight ratios of $\mathrm{CuO}$ with either the $\mathrm{CaO}$ or alumina-based cement as the support material. The detailed compositions of the support materials are given in Table 1. 
Table 1: Properties of reagents used in oxygen carrier preparation

\begin{tabular}{|c|c|c|c|}
\hline & CuO Johnson Matthey & $\begin{array}{l}\text { Alumina-based cement } \\
\text { (Almatis) 'Alpha-bond 300' }\end{array}$ & $\begin{array}{l}\text { Limestone } \\
\text { Longcliffe (UK) }\end{array}$ \\
\hline Composition & $\mathrm{CuO}(\min \sim 98 \%)$ & $\begin{array}{l}\mathrm{Al}_{2} \mathrm{O}_{3}(\min \sim 88 \%) \\
\mathrm{CaO}(\max \sim 0.1 \%) \\
\mathrm{Na}_{2} \mathrm{O}(\max \sim 0.5 \%) \\
\mathrm{SiO}_{2}(\max \sim 0.3 \%)\end{array}$ & $\mathrm{CaCO}_{3}(\min \sim 98 \%)$ \\
\hline $\begin{array}{l}\text { Particle size } \\
\text { (as received) }\end{array}$ & $\begin{array}{l}120 \mu \mathrm{m}(100 \% \text { passing }) \\
70 \mu \mathrm{m}(20 \% \text { passing })\end{array}$ & $\begin{array}{l}90 \mu \mathrm{m}(\max \sim 30 \%) \\
50 \mu \mathrm{m}(\min \sim 4 \%) \\
50 \mu \mathrm{m}(\max \sim 8 \%)\end{array}$ & $\begin{array}{l}600 \mu \mathrm{m}(100 \% \text { passing }) \\
425 \mu \mathrm{m}(85-95 \% \text { passing }) \\
300 \mu \mathrm{m}(60-85 \% \text { passing }) \\
212 \mu \mathrm{m}(30-50 \% \text { passing }) \\
150 \mu \mathrm{m}(10-20 \% \text { passing }) \\
45 \mu \mathrm{m} \text { (min 4\%) }\end{array}$ \\
\hline $\begin{array}{l}\text { Particle size } \\
\text { (After crushing in } \\
\text { ball mill) }\end{array}$ & \multicolumn{3}{|c|}{$80 \% 10 \mu \mathrm{m}$ or less (Malvern Mastersizer 2000) } \\
\hline
\end{tabular}

\subsection{Particle production}

The reagents used in this investigation were of too large particle size to be used as received. Therefore, prior to the production of the oxygen carriers, the reagents were crushed in a ball mill (Orto-Alesa). The defined ratio of copper and support material (totalling $1 \mathrm{~kg}$ ) were added to the ball mill drum along with $1 \mathrm{~kg}$ of $10 \mathrm{~mm}$ hardened stainless steel ball bearings. The ball mill was operated for $24 \mathrm{~h}$ at $100 \mathrm{rpm}$. The production method of oxygen carriers explored in this work was based on a pelletisation method [16], which utilised a table-top TGM granulator manufactured by Glatt.

The mechanical mixing manufacturing method was employed here for its scalability as well as its economy for resources and lower costs compared to other production techniques. In comparison to methods such as freeze granulation, co-precipitation, sol-gel and wet impregnation, mechanical mixing offers a greater degree of scalability and reduction in waste products from the manufacturing process [17]. Typically, copper-based oxygen carriers are not suited to being produced by mechanical mixing due to poor mechanical strength. However, the granulation production method is shown to work well in producing calcium looping sorbents $[18,19]$ and could offer a scalable and economic method for producing copper-based oxygen carriers with robust supports including $\mathrm{CaO}$, that have the potential for enhanced mechanical properties.

The granulator consists of a mixing vessel, in which high-shear rotating blades are mounted horizontally and vertically. These blades are designated the agitator and chopper, respectively. The fine powdered reagents produced in the ball mill were weighed to the desired quantities. Then, they were transferred to the mixing vessel. The rpm of the agitator and the chopper were set to 500 and 2500 , respectively. Water was then added to the powdered mixture, introduced through a pressurised spray nozzle system which could be turned on or off as 
desired. The water spray was added for $10 \mathrm{~s}$ at intervals of $60 \mathrm{~s}$. After each minute, the process was discontinued to visually inspect the mixture to ensure no over-saturation and correct grain size. The effect of over-saturation in a short period of time would lead to particle sizes larger than those desired.

When Al300 was the support material, approximately 150-200 mL of water was added per $\mathrm{kg}$ of powdered mixture. When $\mathrm{CaO}$ was used as the support, the addition of water causes the formation of $\mathrm{Ca}(\mathrm{OH})_{2}$ in an exothermic reaction. Therefore, a greater quantity of water was required to form the pelletised oxygen carriers due to the loss of water through evaporation from the heat released from the reaction. The extent of water loss varied strongly with the $\%$ wt. ratio of $\mathrm{CaO}$ used as a support. Typically, between $300-500 \mathrm{~mL}$ of water was added per $\mathrm{kg}$ of powdered material. The formed particles were then transferred to an alumina tray for airdrying at $200{ }^{\circ} \mathrm{C}$. The particles were then sintered at $900{ }^{\circ} \mathrm{C}$ in a furnace for $4 \mathrm{~h}$. Following the sintering step, the pelletised oxygen carriers were sieved to the desired size range of 355 $425 \mu \mathrm{m}$.

The oxygen carriers produced by the pelletisation technique were effectively spherical, making them suitable for fluidised bed operation. However, the size range of oxygen carrier was dictated by a combination of time in the granulator and the quantity of water added. With the correct management of water addition and time, one batch can typically produce $60 \%$ of particles in the required size range. In particular, $\mathrm{Cu}$ based carriers are always prepared with a support material to avoid problems with sintering and potential attrition []

\subsection{Oxygen carrier characterisation}

The produced oxygen carriers were characterised by X-ray diffraction crystallography (XRD) by means of a Siemens D5005 $\left(2 \theta=10-90^{\circ}\right)$ and by scanning electron microscopy (SEM) Philips XL30 with Schottky Field Emission Gun (SFEG) mode for high-resolution imaging. The SEM was also coupled with energy-dispersive X-ray (EDX) spectroscopy analysis by Oxford Instruments Swift-ED and analysed by Aztex systems software. The crushing strength of the particles was determined by a Shimpo FGN-5 load cell, which is applicable for particles in a size range between $325-425 \mu \mathrm{m}$.

\subsection{Experimental setup and conditions}

The investigation into gaseous fuel conversion was conducted in a quartz fluidised bed reactor (FBR) heated by an external furnace as shown in Figure 2. The reactor height was $550 \mathrm{~mm}$ with an internal diameter of $24 \mathrm{~mm}$. The distribution plate consisted of sintered porous quartz (porosity grade 1) and was located $100 \mathrm{~mm}$ above the bottom of the reactor. The FBR utilised mixtures of $\mathrm{N}_{2}$ and air, $\mathrm{N}_{2}, \mathrm{CO} 10 \%$ in $\mathrm{N}_{2}$ balance and $\mathrm{CH}_{4} 5 \%$ in $\mathrm{N}_{2}$ balance, all supplied from gas cylinders from BOC Ltd using three Bronkhorst (EL-FLOW series) mass flow controllers to control the flow rate. A portion of the exhaust gases from the FBR was sampled continuously by a means of a pump using an approximate flow rate of $0.5 \mathrm{~L} \mathrm{~min}^{-1}$ through a $6.25 \mathrm{~mm}$ OD stainless steel tube inserted $100 \mathrm{~mm}$ into the top of the quartz reactor. A particle filter protected the downstream analysis equipment and a moisture trap with a $\mathrm{CaCl}_{2}$ drying agent, which ensured the gas sample was dry. The sampled gas was analysed at a frequency of $1 \mathrm{~Hz}$ by an ABB EL3020 series multi gas analyser, which measured the gas flows of CO, 
$\mathrm{CO}_{2}, \mathrm{CH}_{4}\left(0-20\right.$ vol\%) and $\mathrm{O}_{2}(0-25$ vol\%). Temperature measurements of the bed were made with a K-type thermocouple inserted into the fluidised bed reactor. The differential pressure was measured across the bed using an Omega PX138 pressure transducer to ensure the bed was fluidised throughout the investigations.

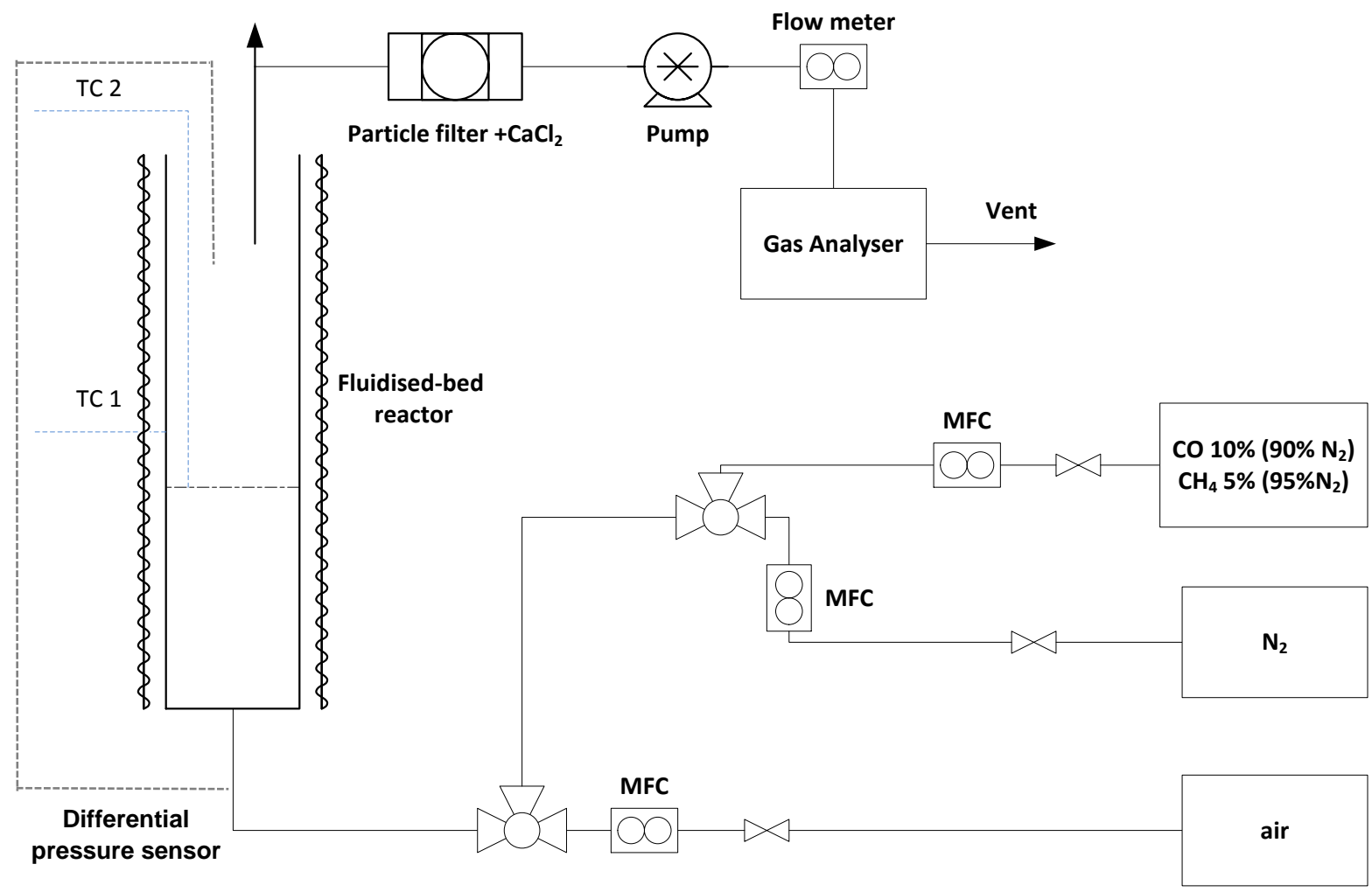

Figure 2: Simplified scheme of fluidised bed reactor for redox investigation

The experimental setup described above was used to investigate the cyclic performance of oxygen carriers with varying ratios of $\mathrm{CuO}$ as the active phase supported by either $\mathrm{CaO}$ or Al300. The oxygen carriers were fluidised in the bubbling regime and were subjected to 25 redox cycles. All investigations were conducted at $950^{\circ} \mathrm{C}$. As both the oxidation and reduction reactions of $\mathrm{CuO} / \mathrm{Cu}_{2} \mathrm{O}$ are exothermic, the oxygen carrier was diluted with silica sand (325-450 $\mu \mathrm{m}$ from Sigma Aldrich) in order to help control the bed temperature. In the investigation, approximately $1.5 \mathrm{~g}$ of oxygen carrier was used together with $13.5 \mathrm{~g}$ of silica sand. A blank cycle was conducted with sand only for calibration of the analysers and to determine whether there were any side reactions of the reactor material with the oxidation and reduction gases. Each redox cycle consisted of 4 stages: 1) inert stage with $\mathrm{N}_{2}$ for a period of $300 \mathrm{~s}, 2$ ) reduction stage with $\mathrm{CO} 10 \%$ in $\mathrm{N}_{2}$ balance or $\mathrm{CH}_{4} 5 \%$ in $\mathrm{N}_{2}$ balance for a period of $60 \mathrm{~s}, 3$ ) sweeping stage with $\mathrm{N}_{2}$ for $60 \mathrm{~s}, 4$ ) oxidation stage with air $20 \%$ with $\mathrm{N}_{2}$ balance for $360 \mathrm{~s}$. The air in the oxidation stage was diluted with nitrogen to give an $\mathrm{O}_{2}$ concentration of $5 \%$. The rate of the oxidation phase in copper-based oxygen carriers is rapid. Using an oxidation period of $360 \mathrm{~s}$ ensures and assumes that the oxygen carrier is fully oxidised prior to the subsequent inert and reduction phases. The inlet gas flows were maintained at a combined $30 \mathrm{~mL} \mathrm{~s}^{-1}$ measured at standard conditions $\left(20^{\circ} \mathrm{C}\right.$ and $\left.101.3 \mathrm{kPa}\right)$ for all the gaseous reaction environments. This corresponded to a ratio of superficial fluidising gas velocity $\left(U_{0}\right)$ to 
minimum fluidisation velocity $\left(U_{m f}\right)$ of approximately 4 , giving rise to a vigorously bubbling bed. The gaseous operating conditions are listed in Table 2.

Table 2: Experimental conditions, gases and flow rates

\begin{tabular}{|c|c|c|c|c|}
\hline Condition & Gas composition & Time (s) & Gas flowrate $\left(\mathrm{L} \min ^{-1}\right)$ & Temperature $\left({ }^{\circ} \mathbf{C}\right)$ \\
\hline Inert & $\mathrm{N}_{2}$ & 300 & 1.8 & 950 \\
\hline Reduction & $\begin{array}{l}10 \% \mathrm{CO}\left(\mathrm{N}_{2} \text { balance }\right) \\
5 \% \mathrm{CH}_{4}\left(\mathrm{~N}_{2} \text { balance }\right)\end{array}$ & 60 & 1.8 & 950 \\
\hline Inert & $\mathrm{N}_{2}$ & 60 & 1.8 & 950 \\
\hline Oxidation & $5 \% \mathrm{O}_{2}\left(20 \%\right.$ air, $\mathrm{N}_{2}$ balance $)$ & 360 & $\begin{array}{l}\text { Air } 0.45 \\
\mathrm{~N}_{2} 1.35\end{array}$ & 950 \\
\hline
\end{tabular}

\subsection{Data evaluation}

The degree of oxygen carrier conversion $(X)$ in this investigation is defined in Equation 1 and is used to describe the extent to which the oxygen carrier can be reduced. $(m)$ is the mass of the sample at a given time $(i),\left(m_{r e d}\right)$ is the mass of the fully reduced sample and $\left(m_{o x}\right)$ is the mass of the fully oxidised sample.

$$
X=\frac{m_{i}-m_{r e d}}{m_{o x}-m_{r e d}}
$$

Equation 1

$\left(X_{\text {red }}\right)$ is used to determine the mass-based conversion across a fuel reduction cycle and is defined for $\mathrm{CH}_{4}$ and $\mathrm{CO}$ in Equation 2 and Equation 3, respectively. $\left(P_{i, \text { out }}\right)$ is the concentration of the gaseous species leaving the reactor, $\left(n_{t o t, i n}\right)$ is the total number of gaseous moles entering the reactor in $\mathrm{mol} \mathrm{s}^{-1},\left(M_{C u O}\right)$ is the molecular weight of $\mathrm{CuO}$ in $\mathrm{g} \mathrm{mol}^{-1}$. $\left(a_{o c}\right)$ is the mass fraction of active metal oxide in the oxygen carrier and $\left(m_{o c}\right)$ is the mass of the oxygen carrier sample. The yield of gas conversion $(\gamma)$ can be calculated with Equation 4 and Equation 5, where $P_{i}$ denotes the partial pressure of the gaseous component $i$ [20].

$$
\begin{array}{cc}
X_{\text {red }}=X_{\text {red }-1}-\int_{t_{-1}}^{t} \frac{n_{\text {tot }, \text { in }} \cdot M_{C u O}}{m_{O C} \cdot a_{O C}} \cdot\left(4 P_{C O_{2, \text { out }}}+3 P_{C O_{\text {out }}}+2 P_{O_{2, \text { out }}}\right) d t & \text { Equation 2 } \\
X_{\text {red }}=X_{\text {red }-1}-\int_{t_{-1}}^{t} \frac{n_{t o t, \text { in }} \cdot M_{C u O}}{m_{O C} \cdot a_{O C}} \cdot\left(2 P_{C O_{2, \text { out }}}+P_{C O_{\text {out }}}+2 P_{O_{2, \text { out }}}\right) d t & \text { Equation 3 } \\
\gamma_{\mathrm{CH}_{4}}=\frac{P_{C O_{2}}}{P_{\mathrm{CO}_{2}}+P_{C O}+P_{C H_{4}}} & \text { Equation 4 }
\end{array}
$$




$$
\gamma_{C O}=\frac{P_{C O_{2}}}{P_{\mathrm{CO}_{2}}+P_{\mathrm{CO}}}
$$

\section{Results and Discussion}

\subsection{Particle characterisation}

Table 3 shows the crushing strength, bulk (tapped) density and the major crystalline phases seen in the freshly pelletised oxygen carriers. The crushing strength was improved with increasing amounts of support material in the oxygen carrier. The average crushing strength of thirty pure $\mathrm{CuO}$ particles was $0.43 \mathrm{~N}$; in comparison to oxygen carriers containing the lowest percentage of support material, the crushing strength improved by a minimum of $280 \%$.

Table 3: Oxygen carrier characterisation properties

\begin{tabular}{llll}
\hline Name of OC & Crushing strength $(\mathbf{N})$ & Bulk (tapped) density $\left(\mathbf{k g ~ m}^{-\mathbf{3}}\right)$ & Major crystalline phases \\
\hline Cu25A175 & 1.55 & 1680 & Bohmite, Tenorite \\
Cu50A150 & 1.27 & 2680 & Corundum, Tenorite \\
Cu75A125 & 1.23 & 3510 & Corundum, Tenorite \\
Cu25Ca75 & 1.63 & 2220 & Portlandite, Tenorite \\
Cu50Ca50 & 1.50 & 2219 & Portlandite, Tenorite \\
Cu75Ca25 & 1.31 & 3320 & Portlandite, Tenorite, \\
& & & $\mathrm{Ca}_{2} \mathrm{CuO}_{3}$ (orthorhombic) \\
\hline
\end{tabular}

The major crystalline phases in the produced oxygen carrier particles were determined by XRD spectrometry. Their diffraction spectra are shown in Figure 3 and Figure 4 for Al300 and $\mathrm{CaO}$ supports, respectively. There are no significant differences between phases seen in the diffraction spectra, with exceptions in $\mathrm{Cu} 25 \mathrm{~A} 175$ where the presence of Bohmite was identified, which typically should not be present, when the samples were calcined at $900^{\circ} \mathrm{C}$ but was still identified. In $\mathrm{CaO}$ supported samples, Portlandite was present in all samples, indicating the samples may have absorbed some atmospheric moisture in storage. The $\mathrm{Cu} 75 \mathrm{Ca} 25$ oxygen carrier saw the presence of a copper calcium compound $\mathrm{Ca}_{2} \mathrm{CuO}_{3}$, which has been reported in previous studies [9]. 

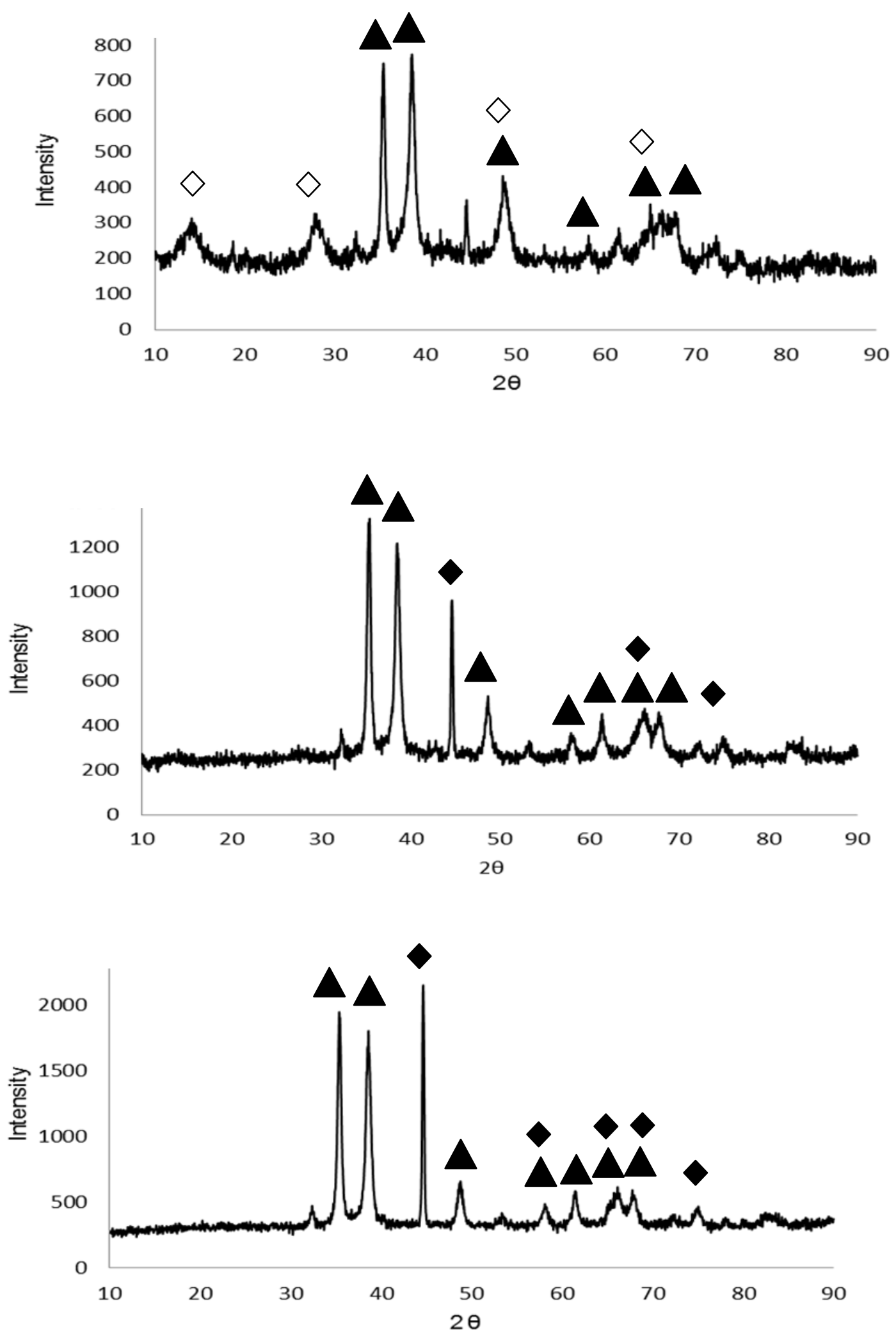

Figure 3: XRD spectra of alumina-supported oxygen carriers (Top)-Cu25Al75 (Centre)-Cu50Al50 (Bottom)$\mathrm{Cu} 75 \mathrm{Al} 25 \mathbf{\Delta}-\mathrm{CuO}$ (Tenorite) $-\mathrm{Al}_{2} \mathrm{O}_{3}$ (Corundum) $\diamond-\mathrm{AlO}(\mathrm{OH})($ Bohmite) 

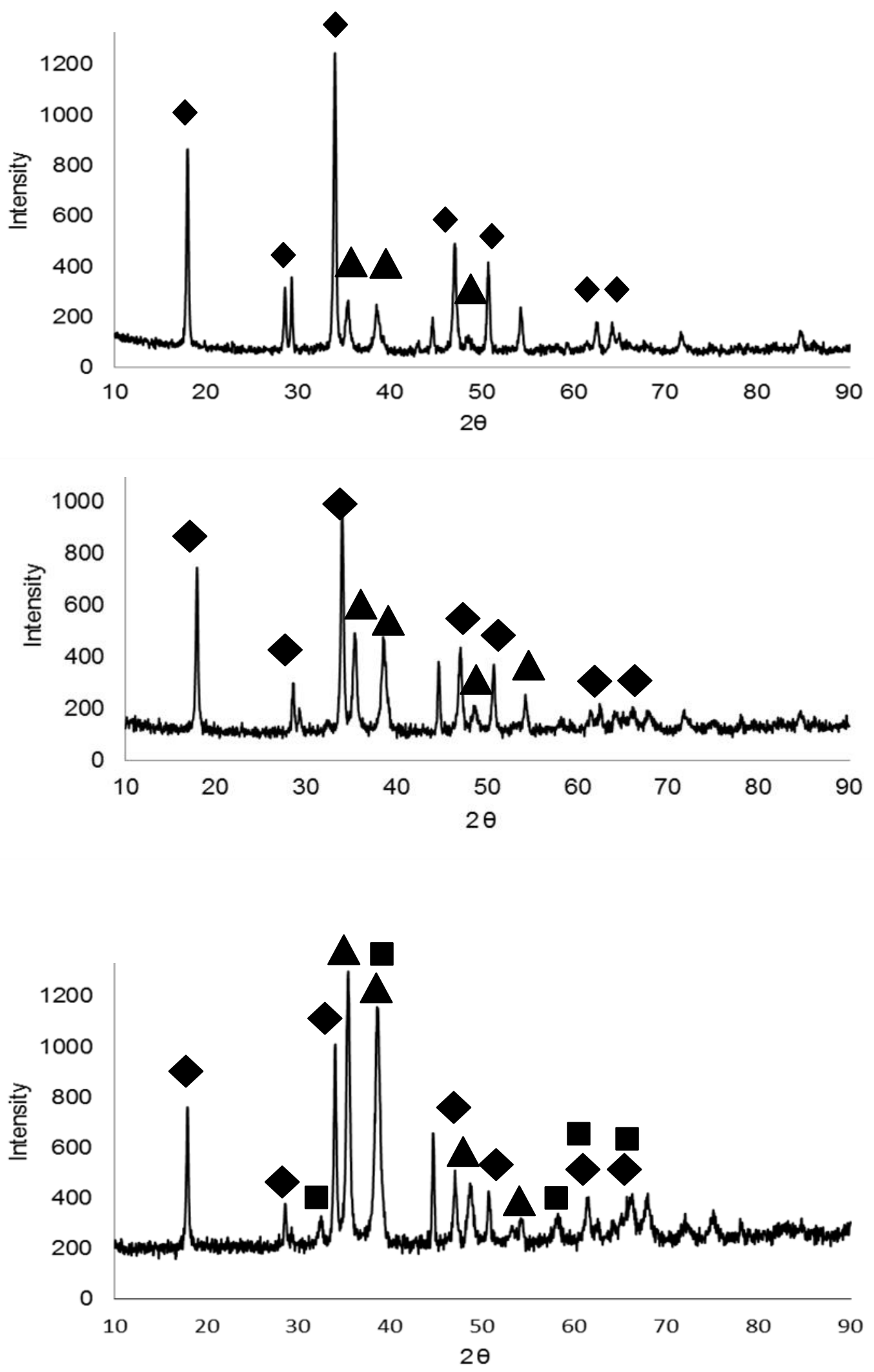

Figure 4: XRD spectra for Ca-supported oxygen carriers (Top)-Cu25Ca75 (Centre)-Cu50Ca50 (Bottom)-

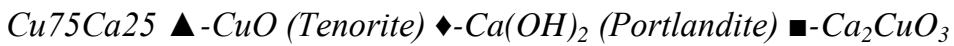


The freshly prepared particles were assessed under SEM in SFEG mode for high-resolution imaging. To investigate the internal composition of the oxygen carriers, the particles were first mounted on an epoxy resin. This resin mould was then ground back to reveal the crosssectional area of the particles. The resin moulds were then assessed under SEM with EDX analysis. This allowed the examination of the uniformity of support material and copper (II) oxide within.

The oxygen carriers containing the Al300 support are shown in Figure 5-7. The nonuniformity of the elemental distribution within the particles shows that the $\mathrm{CuO}$ tends to be localised to specific areas within a given particle. This is also observed in the oxygen carrier particles containing $\mathrm{CaO}$ as a support (Figure 8-10).

The comparison in morphology of the $25 \% \mathrm{CuO}$-containing oxygen carriers clearly shows a difference in support material structure. In Cu25Al75 (Figure 4ii) it appears the Al300 supports were formed of smaller particles and are compacted together with the $\mathrm{CuO}$ to form the oxygen carrier. In contrast to the $\mathrm{Cu} 25 \mathrm{Ca} 75$ (Figure 7ii), the formation of the $\mathrm{CaO}$ support appears to be uniform with a greater distribution of the active $\mathrm{CuO}$ and the increased connectivity with the support is likely a contributing factor for its increased crushing strength over the A1300-supported particles. In the $\mathrm{Cu} 75 \mathrm{Ca} 25$ oxygen carrier XRD indicated the presence of $\mathrm{Ca}_{2} \mathrm{CuO}_{3}$ and this may be present in all the $\mathrm{CaO}$-supported samples, although not as a major identified phase. This mixed compound has a low melting point [9] which could bond particulates and contribute to the increased crushing strength. The pelletisation method favours the use of $\mathrm{CaO}$ as a support material. It can be seen that the $\mathrm{CaO}$-supported oxygen carriers (Figures 8i, 9i and 10i) appear to be more spherical than the Al300-based particles (Figures 5i, 6i and 7i) and can result in more favourable fluidisation properties and less attrition due to reduced fragmentation and 'rounding' of the particles occurring during fluidising operation due to the removal of asperities on the particles. 


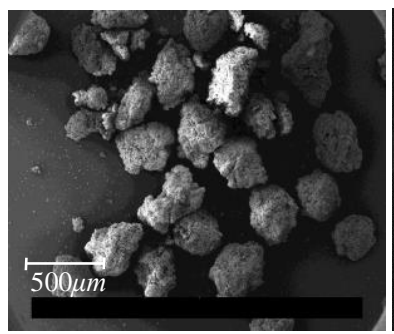

i)

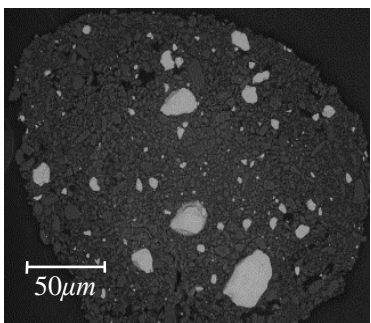

ii)

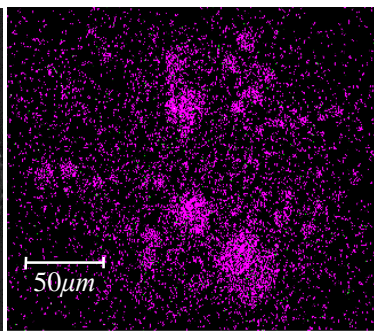

iii)

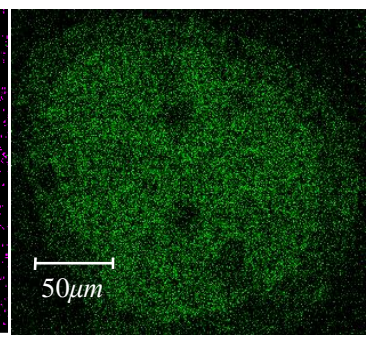

iv)

Figure 5: Cu25Al75 i) High-resolution SFEG image (scale $500 \mu \mathrm{m}$ ), ii) Global particle view EDX, iii) $C$ u elemental mapping EDX, iv) Al elemental mapping EDX

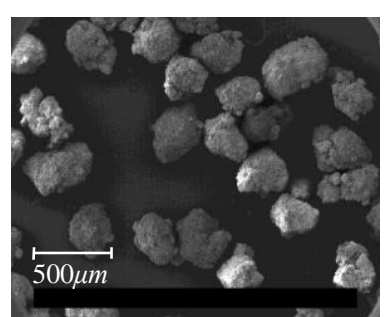

i)

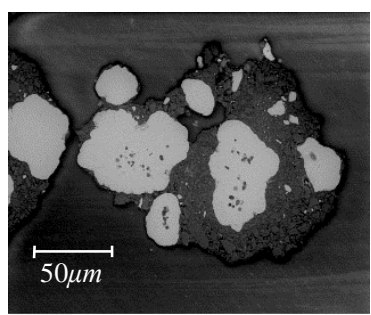

ii)

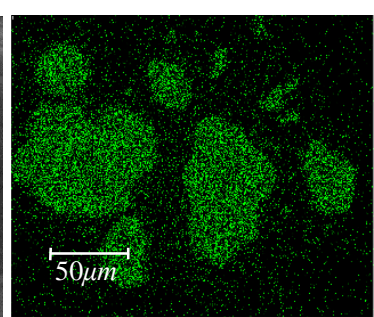

iii)

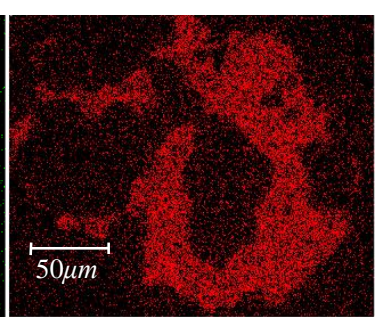

iv)

Figure 6: Cu50Al50 i) High-resolution SFEG image (scale $500 \mu \mathrm{m}$ ), ii) Global particle view EDX, iii) Cu elemental mapping EDX, iv) Al elemental mapping EDX

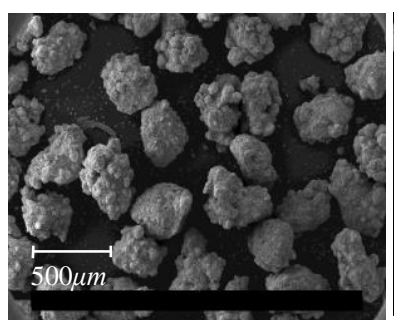

i)

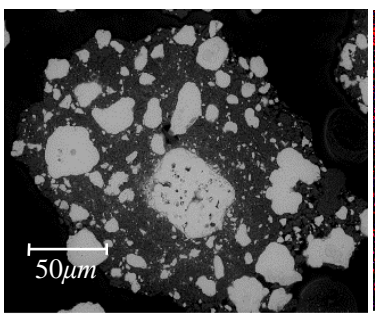

ii)

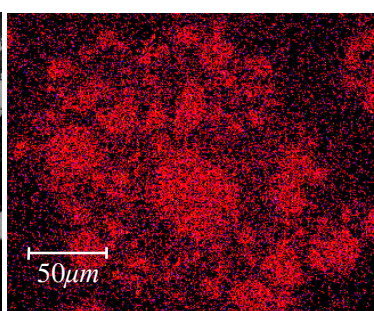

iii)

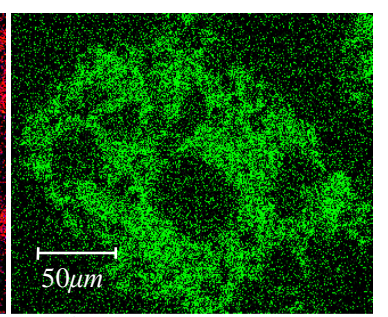

iv)

Figure 7: Cu75Al25 i) High-resolution SFEG image (scale $500 \mu \mathrm{m}$ ), ii) Global particle view EDX, iii) Cu elemental mapping EDX, iv) Al elemental mapping EDX 


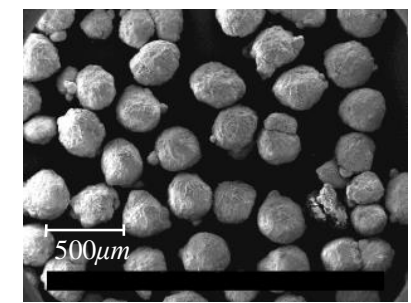

i)

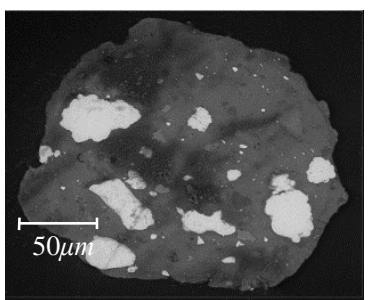

ii)

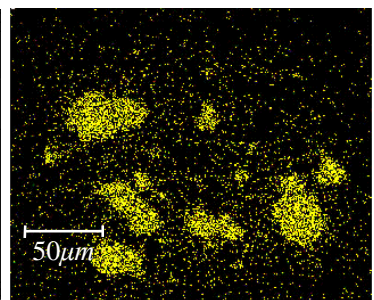

iii)

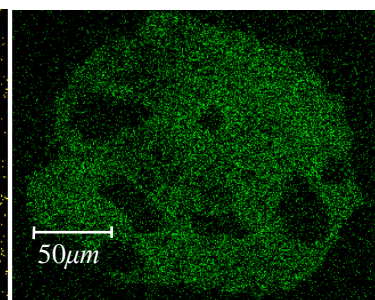

iv)

Figure 8: Cu25Ca75 i) High-resolution SFEG image (scale $500 \mu \mathrm{m}$ ), ii) Global particle view EDX, iii) Cu elemental mapping EDX, iv) Ca elemental mapping EDX

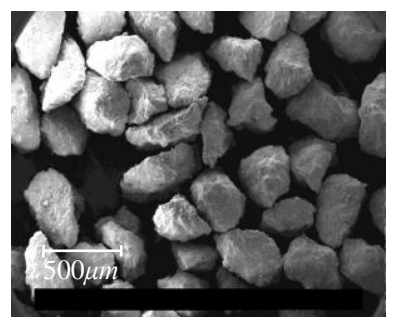

i)

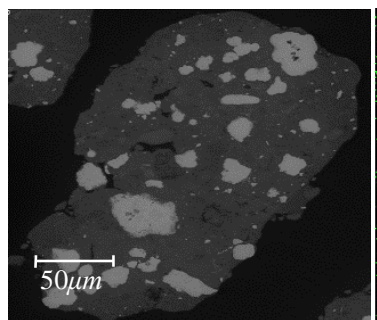

ii)

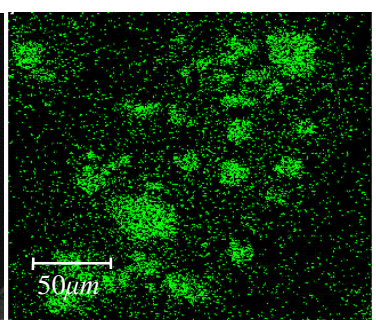

iii)

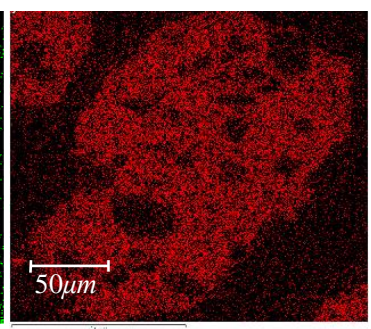

iv)

Figure 9: Cu50Ca50 i) High-resolution SFEG image (scale $500 \mu \mathrm{m}$ ), ii) Global particle view EDX, iii) Cu elemental mapping EDX, iv) Ca elemental mapping EDX

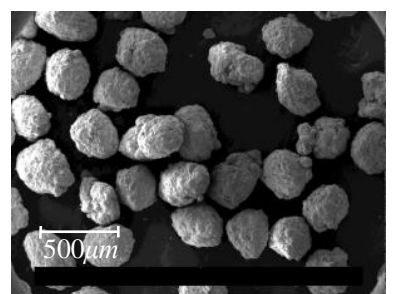

i)

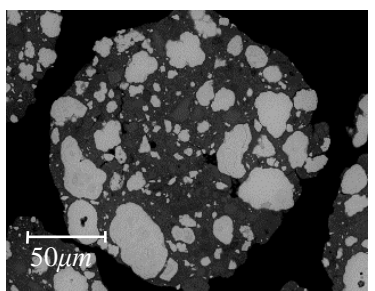

ii)

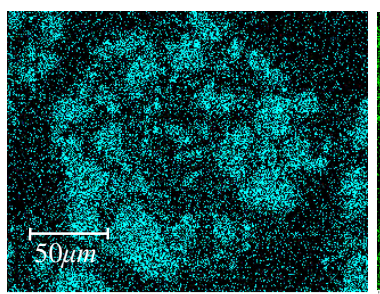

iii)

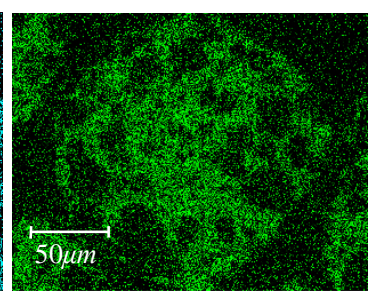

iv)

Figure 10: Cu75Ca25 i) High-resolution SFEG image (scale $500 \mu \mathrm{m}$ ), ii) Global particle view EDX, iii) Cu elemental mapping EDX, iv) Ca elemental mapping EDX

\subsection{Carbon monoxide conversion}

The cyclic redox behaviours of the Al300-supported oxygen carriers were assessed in a fluidised bed with twenty-five alternating oxidation $\left(\mathrm{O}_{2} 5 \%\right)$, reduction $(\mathrm{CO} 10 \%)$ and inert cycles at a temperature of $950{ }^{\circ} \mathrm{C}$. The $\mathrm{CO}$ conversion $\left(\gamma_{\mathrm{CO}}\right)$ as a function of oxygen carrier conversion in the reduction stage $\left(X_{\text {red }}, \mathrm{CuO}-\mathrm{Cu}\right)$ is shown in Figure 11 for $\mathrm{Al} 300$-supported oxygen carriers. The oxidising phase was sufficiently fast, and the length of the time of this period (360 s) ensured and assumes full oxidation. In all the investigations, the reduction step was sufficiently fast to ensure that the $\mathrm{CO}$ was fully converted by the oxygen carrier, thereby successfully reducing the active phase $\mathrm{CuO}$ to $\mathrm{Cu}$. This is confirmed by all the oxygen carriers reaching a solid reduction conversion $\left(X_{\text {red }}, \mathrm{CuO}-\mathrm{Cu}\right)>0.9$. Comparing each specific oxygen carrier, the shape of the curve changes in relation to the degree of $\mathrm{CO}$ conversion and reducibility of the carrier. This is fairly indicative of the content of active $\mathrm{CuO}$ present. An 
increase in activation or deactivation with accumulating redox cycles can be seen where the gas yield becomes reduced or increases with the effect of accumulating cycles. The general trend is followed throughout the investigation where the increased content of active $\mathrm{CuO}$ gives an increased $\mathrm{CO}$ conversion yield. The general shapes of the curves for each of the oxygen carriers become increasingly horizontal, with a $\mathrm{CO}$ conversion yield closer to unity indicating greater conversion of $\mathrm{CO}$ to $\mathrm{CO}_{2}$ with increased $\mathrm{CuO}$ content. In cycle 1 of $\mathrm{Cu} 75 \mathrm{Al} 25$ (Figure 11c), it can be concluded that the entirety of $\mathrm{CO}$ entering the fluidised bed in the reduction period was converted to $\mathrm{CO}_{2}$. All of the Al300-supported oxygen carriers follow a trend whereby the primary redox cycle exhibits the greatest $\mathrm{CO}$ conversion. The produced gas yield is reduced as the redox cycles increase. In Cu25Al75 there is little difference between the curves in cycle 12 and 25, but both show decreased gas yield compared to the first cycle. It can be observed from the curves of Cu50A150 and $\mathrm{Cu} 75 \mathrm{Al} 25$ that there is a greater difference between cycle 12 and 25, which results in a reduced $\mathrm{CO}$ conversion yield. Cu25A175 was the only oxygen carrier to not suffer from agglomeration. Due to the full reduction to elemental $\mathrm{Cu}$, in all of the Al300-supported oxygen carriers, the particles with 50\% and higher $\mathrm{CuO}$ suffered significant agglomeration, indicated by a drop in differential pressure during the cyclic investigations and subsequent visual inspection. Comparisons using high-resolution SEM images of the morphology between Al300-supported fresh prepared particles and those having undergone redox investigations are shown in Figures 12-14.

a)

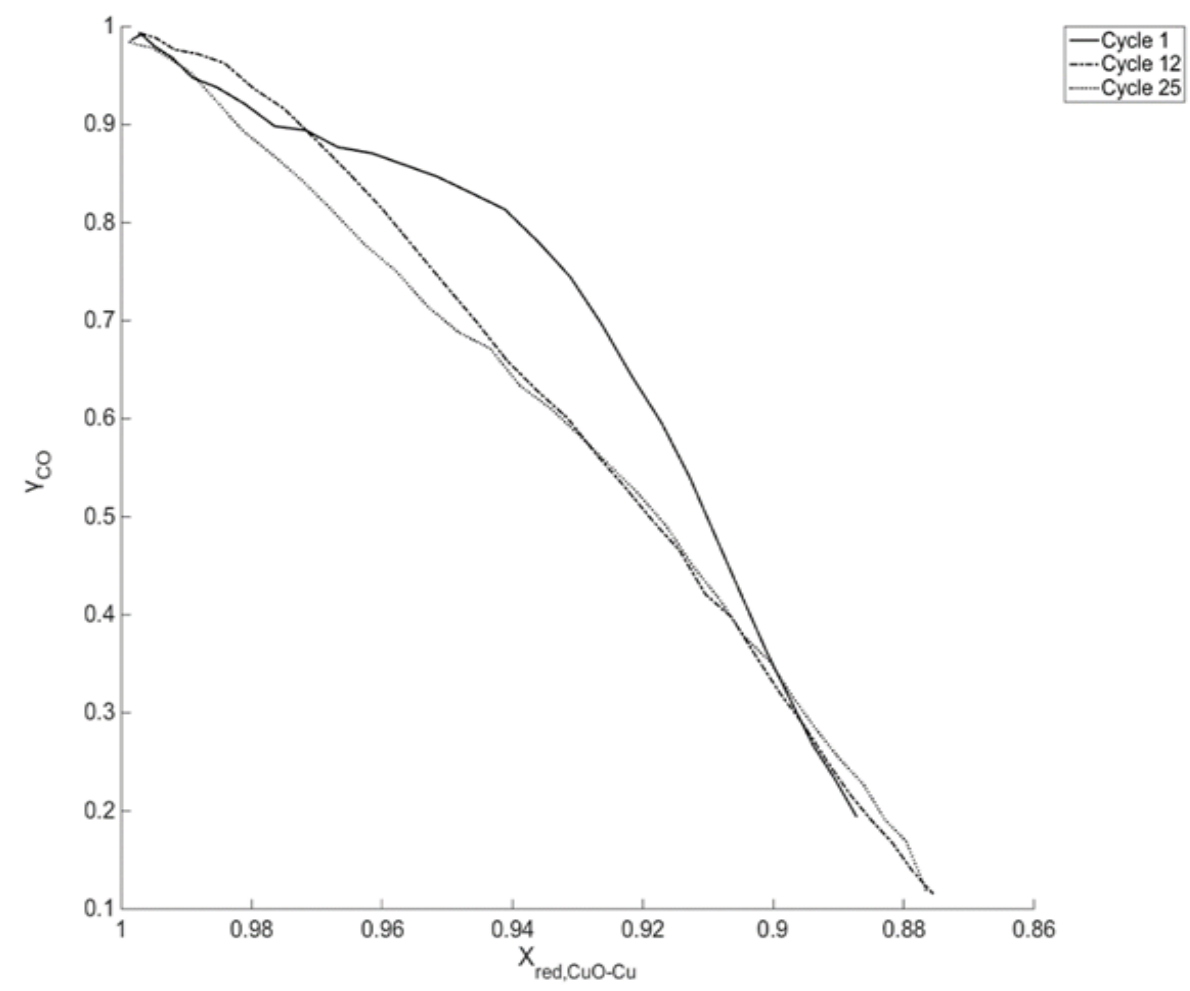


b)

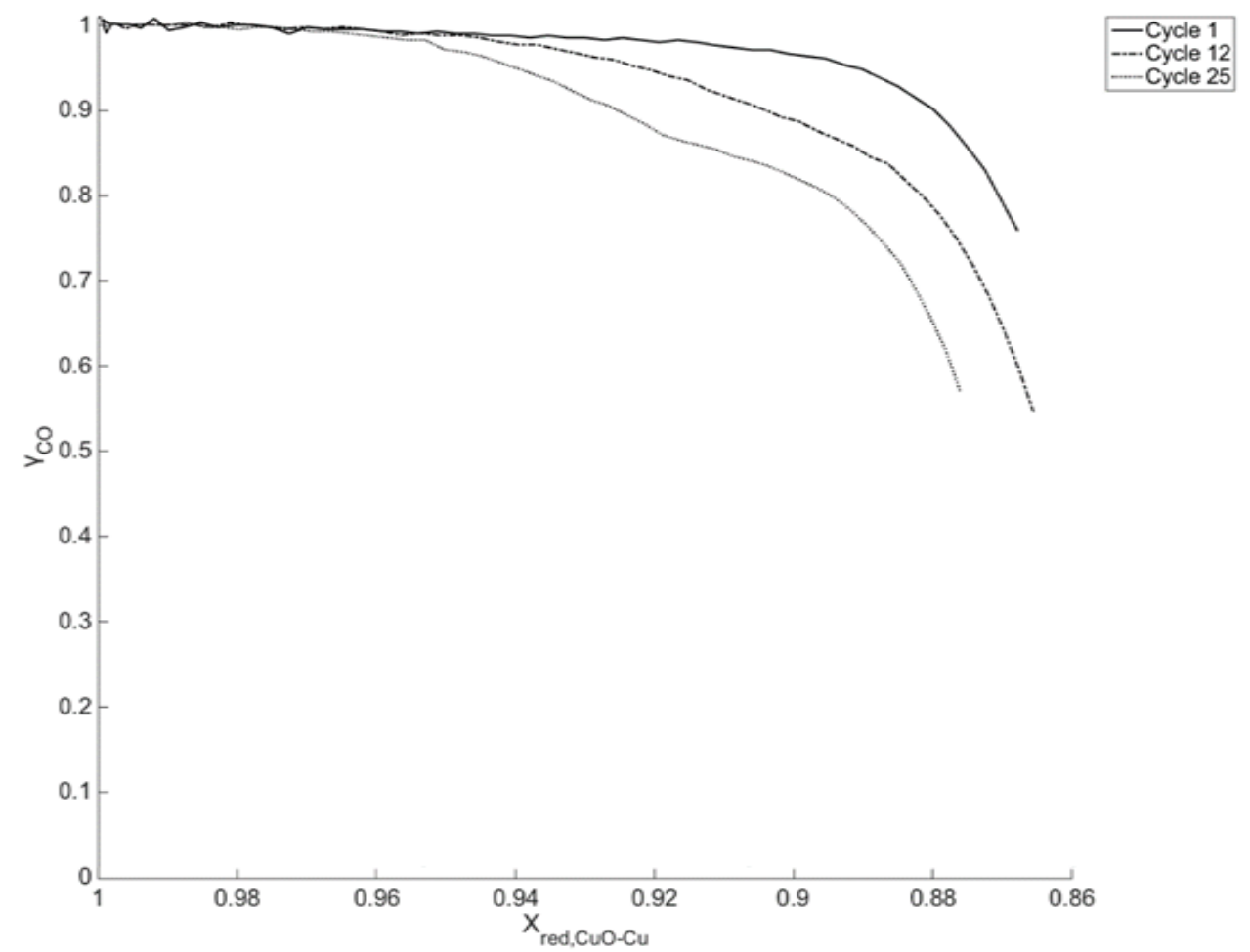

c)

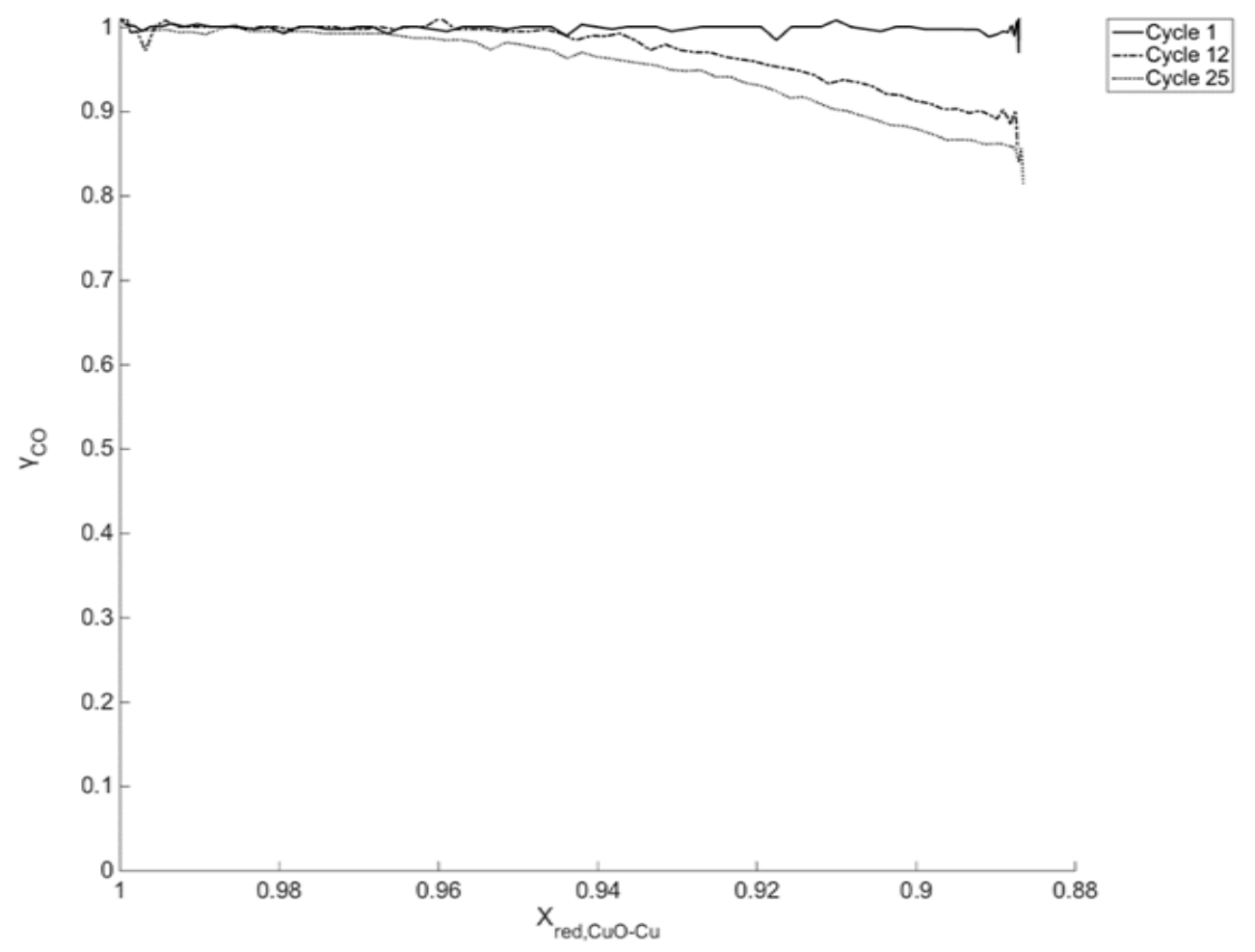

Figure 11: Redox cyclic behaviour over 25 cycles assessed by oxygen carrier conversion vs. the conversion of $\mathrm{CO}$ to $\mathrm{CO}_{2}:$ a) $\mathrm{Cu} 25 \mathrm{Al75}$, b) Cu50Al50, c) Cu75Al25 

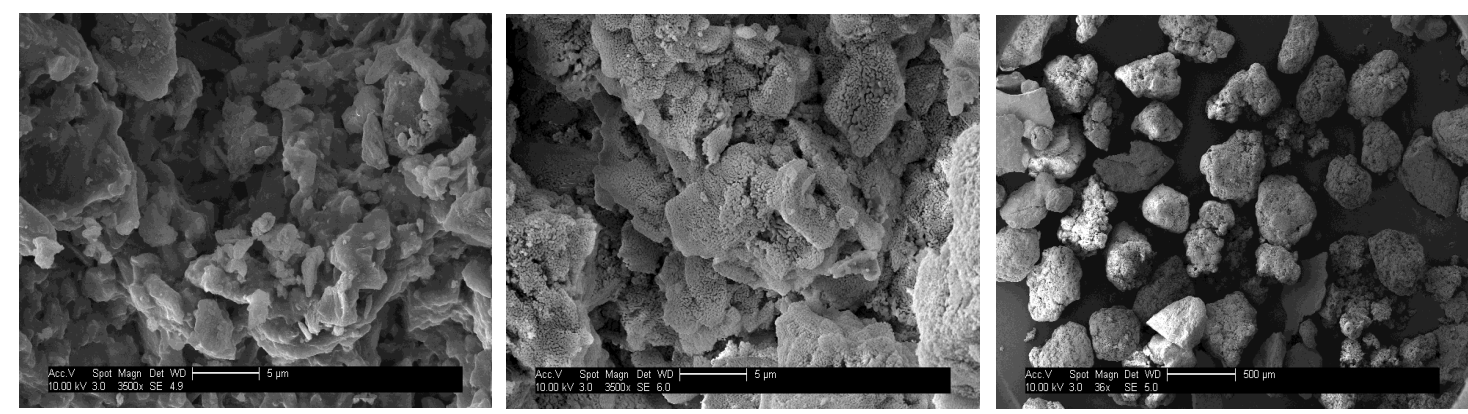

Figure 12: High-resolution SEM images showing morphology of Cu25Al75: (left) Fresh produced 5 um; (centre) After 25 redox cycles with CO $5 \mu \mathrm{m}$; (right) Multiple particles after 25 redox cycles with CO $500 \mu \mathrm{m}$
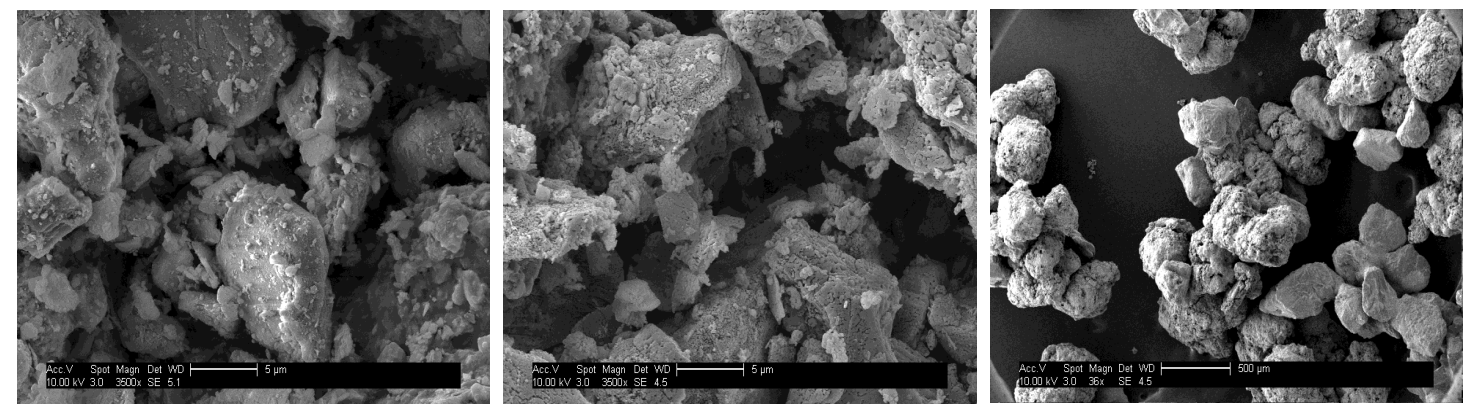

Figure 13: High-resolution SEM images showing morphology of Cu50Al50: (left) Fresh produced 5 $\mu \mathrm{m}$; (centre) After 25 redox cycles with CO $5 \mu \mathrm{m}$; (right) Multiple particles after 25 redox cycles with CO $500 \mu \mathrm{m}$
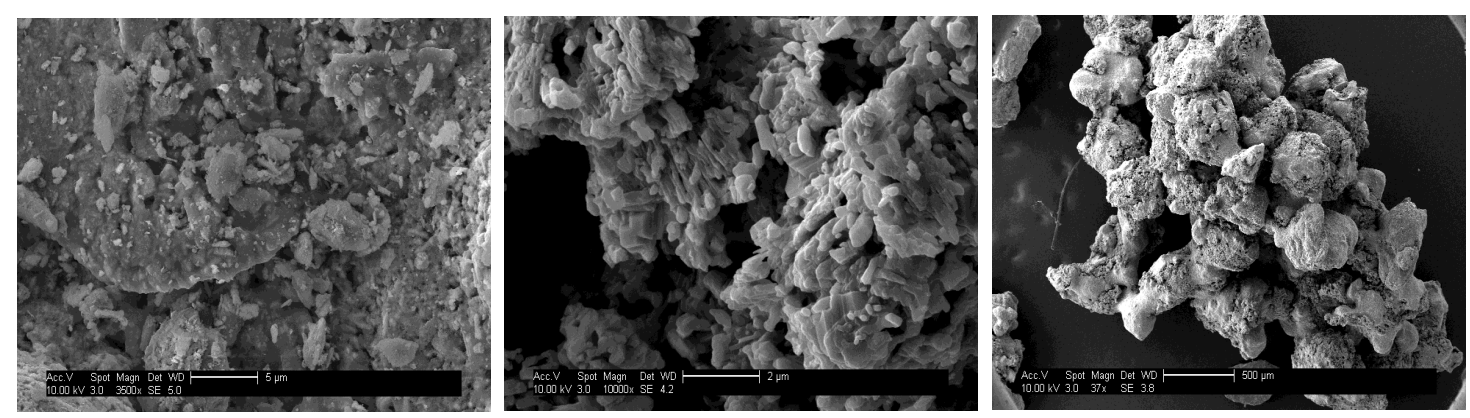

Figure 14: High-resolution SEM images showing morphology of Cu75Al25: (left) Fresh produced 5 $\mu \mathrm{m}$; (centre) After 25 redox cycles with CO $5 \mu \mathrm{m}$; (right) Multiple particles after 25 redox cycles with CO $500 \mu \mathrm{m}$ 
The SEM images of the Cu50Al50 and Cu75Al25 (Figures 13 and 14) taken at $\mathrm{x} 36$ magnification at a scale of $500 \mu \mathrm{m}$ of multiple particles (right) show the extent of the agglomeration of the particles, which is clearly more severe for oxygen carriers with a higher $\mathrm{CuO}$ content. The agglomeration would be detrimental in a circulating fluidised bed process. The general comparison of the morphology between the fresh particles and those subjected to the redox cycles shows increased pore size. The decrease in the ability to convert fuel with increasing redox cycles may have been due to particle agglomeration. A negligible decrease in $\mathrm{CO}$ conversion was observed in redox cycles 12 and 25 in $\mathrm{Cu} 25 \mathrm{Al} 75$, which did not agglomerate. This leads us to conclude that agglomeration may bear an influence on the reduction in $\mathrm{CO}$ conversion and reaction behaviour over increasing redox cycle numbers and increased $\mathrm{Cu}$ content. The SEM analysis (Figures 12-14) also shows pore development. Freshly produced oxygen carrier particles exhibit a micro-porous structure which then develops into macro-pores as observed following the $25^{\text {th }}$ redox cycle. This could limit the conversion of $\mathrm{CO}$ to $\mathrm{CO}_{2}$ and in conjunction with the occurrence of agglomeration, therefore exhibit reaction profiles that follow the trend for decreasing gas conversion with accumulative cycles, especially for samples with 50 and $75 \%$ wt. $\mathrm{Cu}$ content. Fine particulates were recovered at the filter inlet and are an indication of attrition of the oxygen carriers. Cu25A175 particles attrite the most with losses of $7.7 \%$. By contrast, Cu50Al50 and Cu75Al25 represented losses of $2.7 \%$ and $0.25 \%$, respectively.

The cyclic redox behaviour of $\mathrm{CaO}$-supported oxygen carriers is as shown in Figure 15. The $\mathrm{CaO}$-supported oxygen carriers follow the same trend as the alumina-based Al300-supported oxygen carriers where the extent of fuel conversion appears largely due to the ratio of active $\mathrm{CuO}$ present in the oxygen carrier. For $\mathrm{Cu} 25 \mathrm{Ca} 75$ and $\mathrm{Cu} 50 \mathrm{Ca} 50$, the effect of increased fuel conversion with accumulating redox cycles is not as strongly evident as it is in the Al300supported oxygen carriers. The $\mathrm{Cu} 25 \mathrm{Ca} 75$ oxygen carrier improves in reducibility and yield of gas conversion with an increase in redox cycle number. For Cu50Ca50 there is a negligible difference in both reducibility of the oxygen carrier and gas conversion between different cycles. By contrast, for the $\mathrm{Cu} 75 \mathrm{Ca} 25$ oxygen carrier, the effect of subsequent redox cycles is apparent. Here, the ability to convert $\mathrm{CO}$ to $\mathrm{CO}_{2}$ is reduced when compared to the $1^{\text {st }}$ and $12^{\text {th }}$ redox cycles. This oxygen carrier is also subjected to severe agglomeration and can be seen in Figure 18, whereas agglomeration, which was observed in the other $\mathrm{CaO}$-supported oxygen carriers, shown in Figures 16 and 17 for $\mathrm{Cu} 25 \mathrm{Ca} 75$ and $\mathrm{Cu} 50 \mathrm{Ca} 50$, did not occur to the same extent and did not cause de-fluidisation during the testing period. 
a)

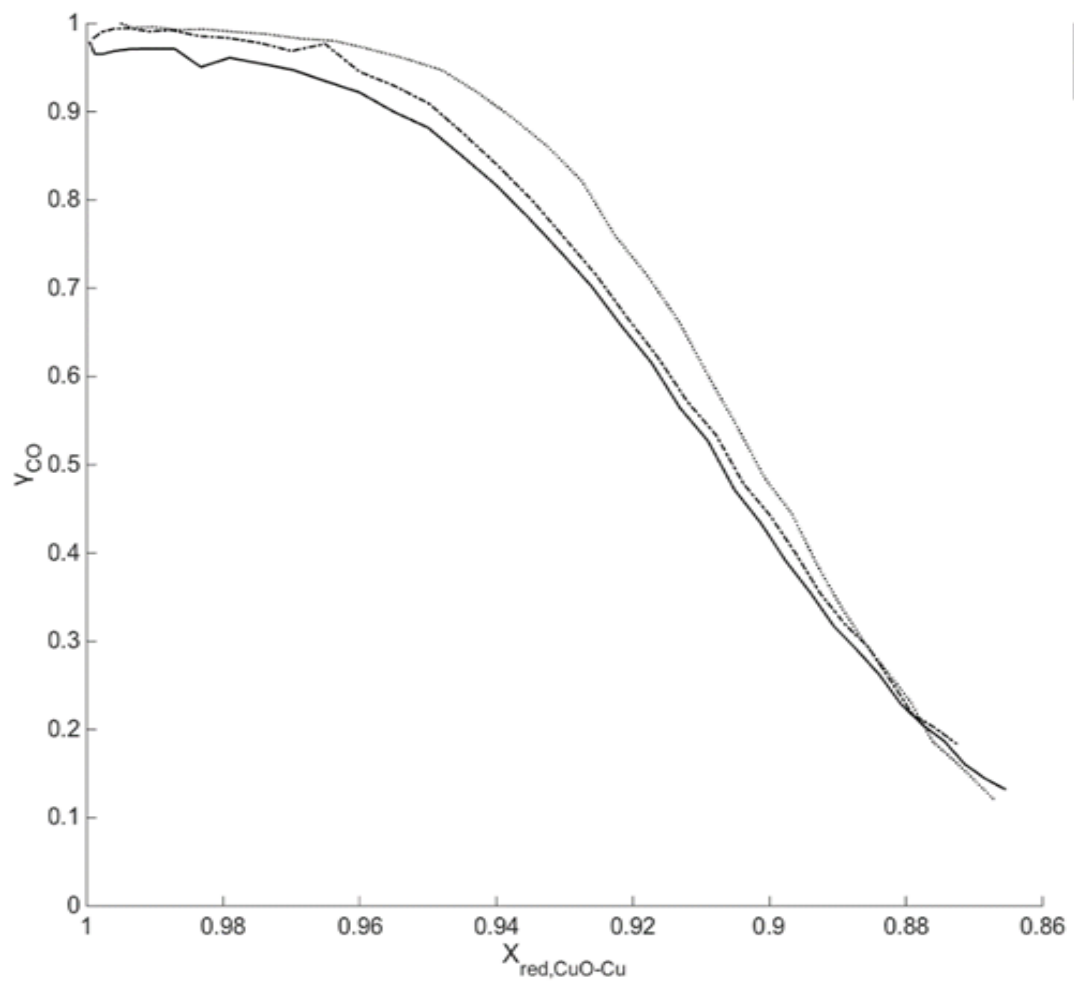

b)

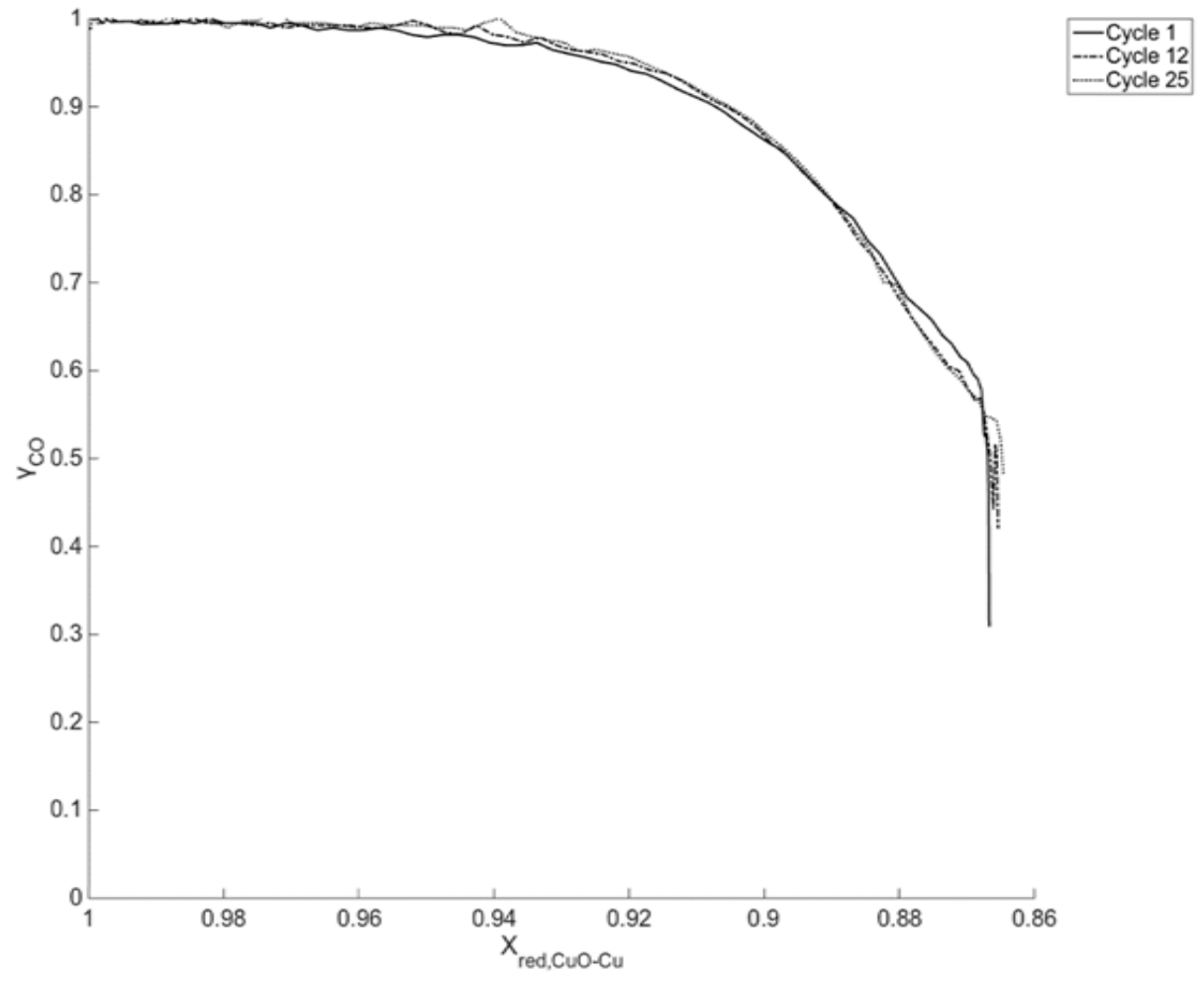


c)

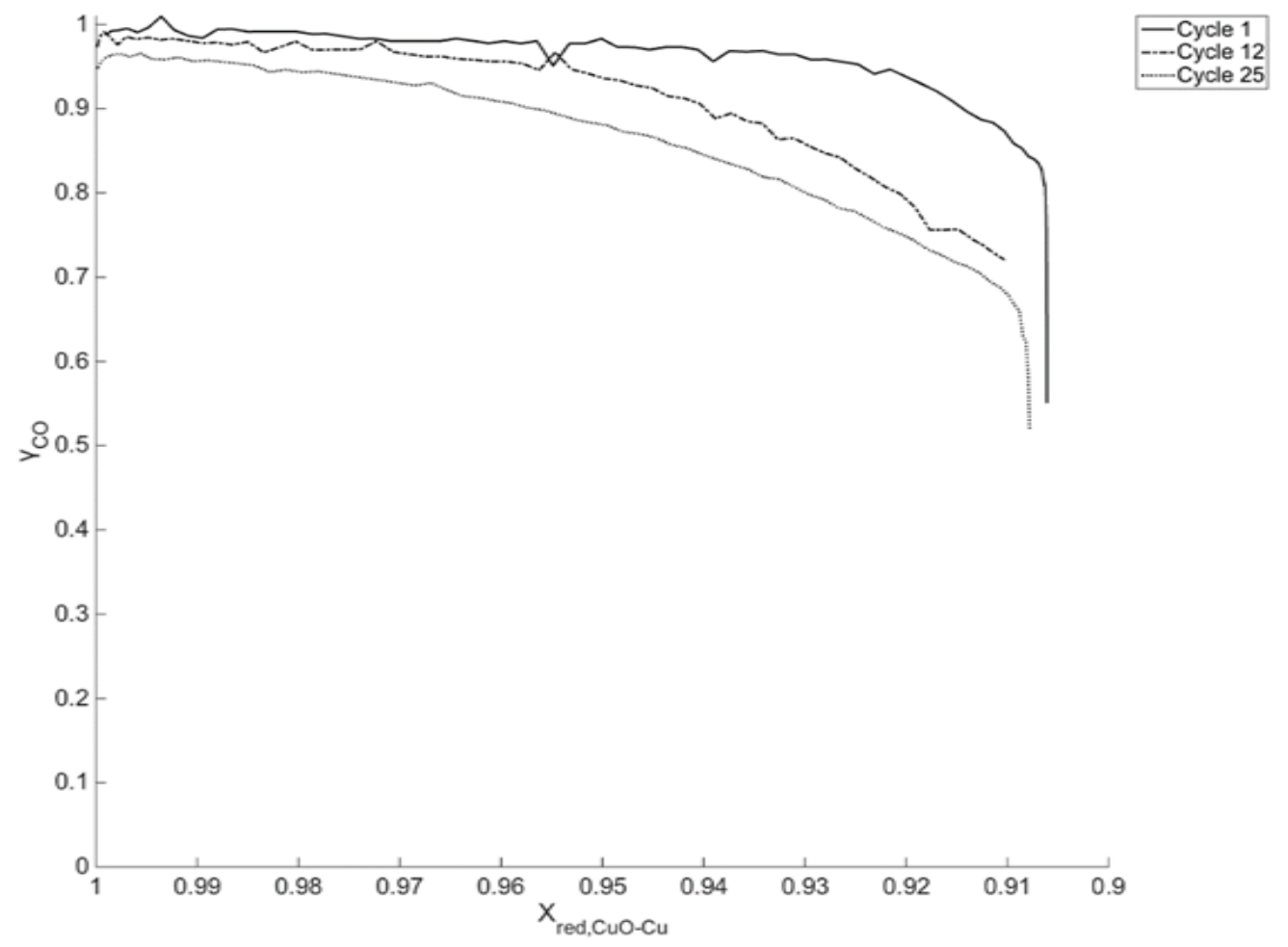

Figure 15: Redox cyclic behaviour over 25 cycles assessed by oxygen carrier conversion vs. the conversion of $\mathrm{CO}$ to $\mathrm{CO}_{2}:$ a) $\mathrm{Cu} 25 \mathrm{Ca} 75$, b) $\mathrm{Cu} 50 \mathrm{Ca} 50$, c) $\mathrm{Cu} 75 \mathrm{Ca} 25$ 

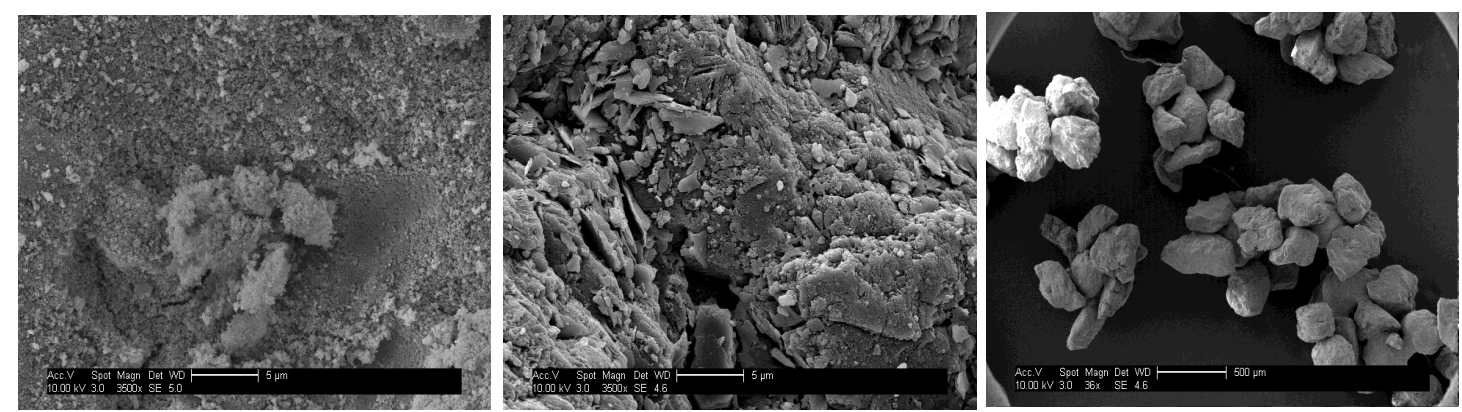

Figure 16: High-resolution SEM images showing morphology of Cu25Ca75: (left) Fresh produced 5 um; (centre) After 25 redox cycles with CO $5 \mu \mathrm{m}$; (right) Multiple particles after 25 redox cycles with CO $500 \mu \mathrm{m}$
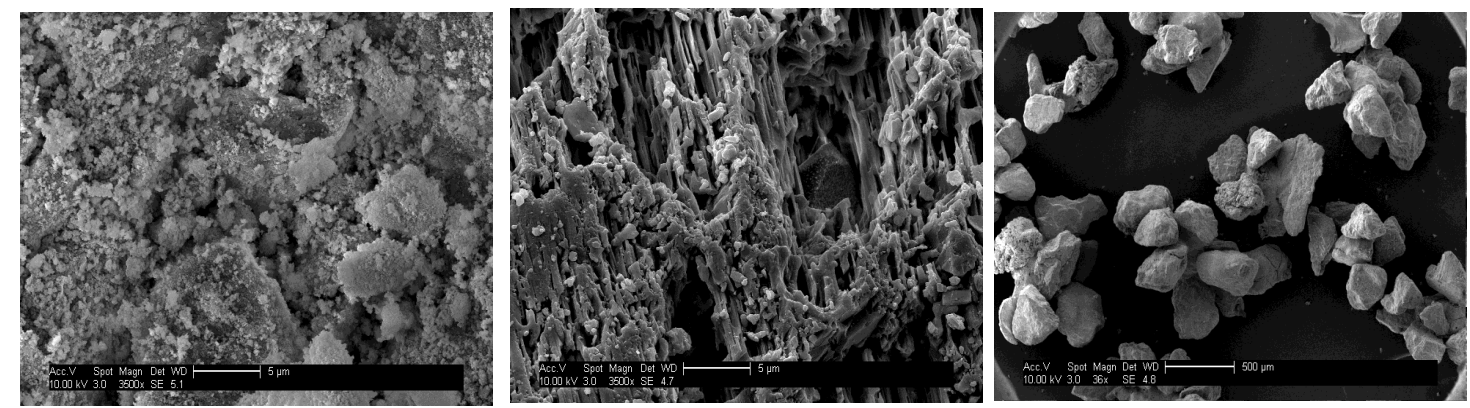

Figure 17: High-resolution SEM images showing morphology of Cu50Ca50: (left) Fresh produced $5 \mu \mathrm{m}$; (centre) After 25 redox cycles with CO $5 \mu \mathrm{m}$; (right) Multiple particles after 25 redox cycles with CO $500 \mu \mathrm{m}$
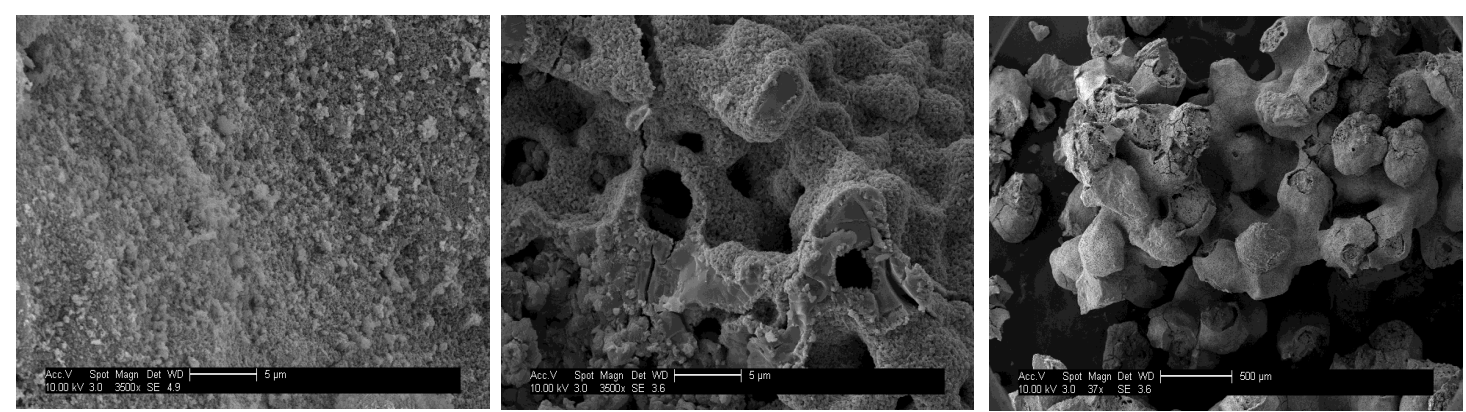

Figure 18: High-resolution SEM images showing morphology of Cu75Ca25: (left) Fresh produced $5 \mu \mathrm{m}$; (centre) After 25 redox cycles with CO $5 \mu \mathrm{m}$; (right) Multiple particles after 25 redox cycles with CO $500 \mu \mathrm{m}$

The changes in pore structure and morphology for the $\mathrm{CaO}$-supported oxygen carriers are shown in the left and centre images in Figures 16-18. The effect of the accumulative redox cycles is significant. Agglomeration is clearly present in the $\mathrm{Cu} 75 \mathrm{Ca} 25$ oxygen carrier and can be attributed to the forming of copper-calcium phases which possess low melting points [9]. It can be observed in all the $\mathrm{CaO}$-supported oxygen carriers that there is an increase in 
porosity, where the micro-pores in the fresh samples developed into macro-pores in the used particles. This effect can initially give rise to greater gas diffusion in the oxygen carrier, allowing a greater surface area for gas conversion to take place [21] and is observed in the $\mathrm{Cu} 25 \mathrm{Ca} 75$ sample. However, the formation of the macro-pores eventually leads to a reduction in surface area, and thus a reduced conversion rate, as seen in the $\mathrm{Cu} 75 \mathrm{Ca} 25$ oxygen carrier. Again, similarly to $\mathrm{Cu} 75 \mathrm{Al} 25$, the increased $\mathrm{Cu}$ content causes these samples to suffer from agglomeration, which, in conjunction with the increased pore development, causes a reduction in gas conversion with accumulative cycles. The $\mathrm{CaO}$-supported oxygen carriers exhibited no significant attrition, as measured from the fines collected at the particulate filter.

\subsection{Methane conversion}

$\mathrm{Cu} 25 \mathrm{Al} 75$ and $\mathrm{Cu} 25 \mathrm{Ca} 75$ are chosen here as the most suitable oxygen carriers for a redox investigation with methane as the reducing gas, following the cyclic experiments for the conversion of CO. These oxygen carriers showed minimal agglomeration. The redox behaviour of the two oxygen carriers with methane is shown in Figure 19 and follows the trends seen in the $\mathrm{CO}$ conversion set of experimental investigations. It is observed that $\mathrm{Cu} 25 \mathrm{Al} 75$ is further reduced and exhibits a higher conversion of methane in comparison to $\mathrm{Cu} 25 \mathrm{Ca} 75$. The methane conversion yield for $\mathrm{Cu} 25 \mathrm{Ca} 75$ is minimal and ranges between 15$25 \%$. The curve shows that the reducibility of this oxygen carrier from $\mathrm{CuO}$ to $\mathrm{Cu}$ is also limited. The conversion of $\mathrm{Cu} 25 \mathrm{~A} 175$ oxygen carrier to $\mathrm{Cu}$ was greater in extent in comparison to $\mathrm{Cu} 25 \mathrm{Ca} 75$ (approximately 50\%). The conversion of $\mathrm{CH}_{4}$ is not complete but comparable to the conversion exhibited by highly engineered oxygen carriers described in previous literature [22]. Similarly to the reduction with $\mathrm{CO}, \mathrm{Cu} 25 \mathrm{Al} 75$ shows a decrease in its performance for reducibility and methane conversion with accumulating redox cycles. This is not observed in $\mathrm{Cu} 25 \mathrm{Ca} 75$, where the effect of increasing redox cycles improves these properties, as can be seen in the comparison of the higher methane conversion yield between the $25^{\text {th }}$ and $1^{\text {st }}$ redox cycle. 


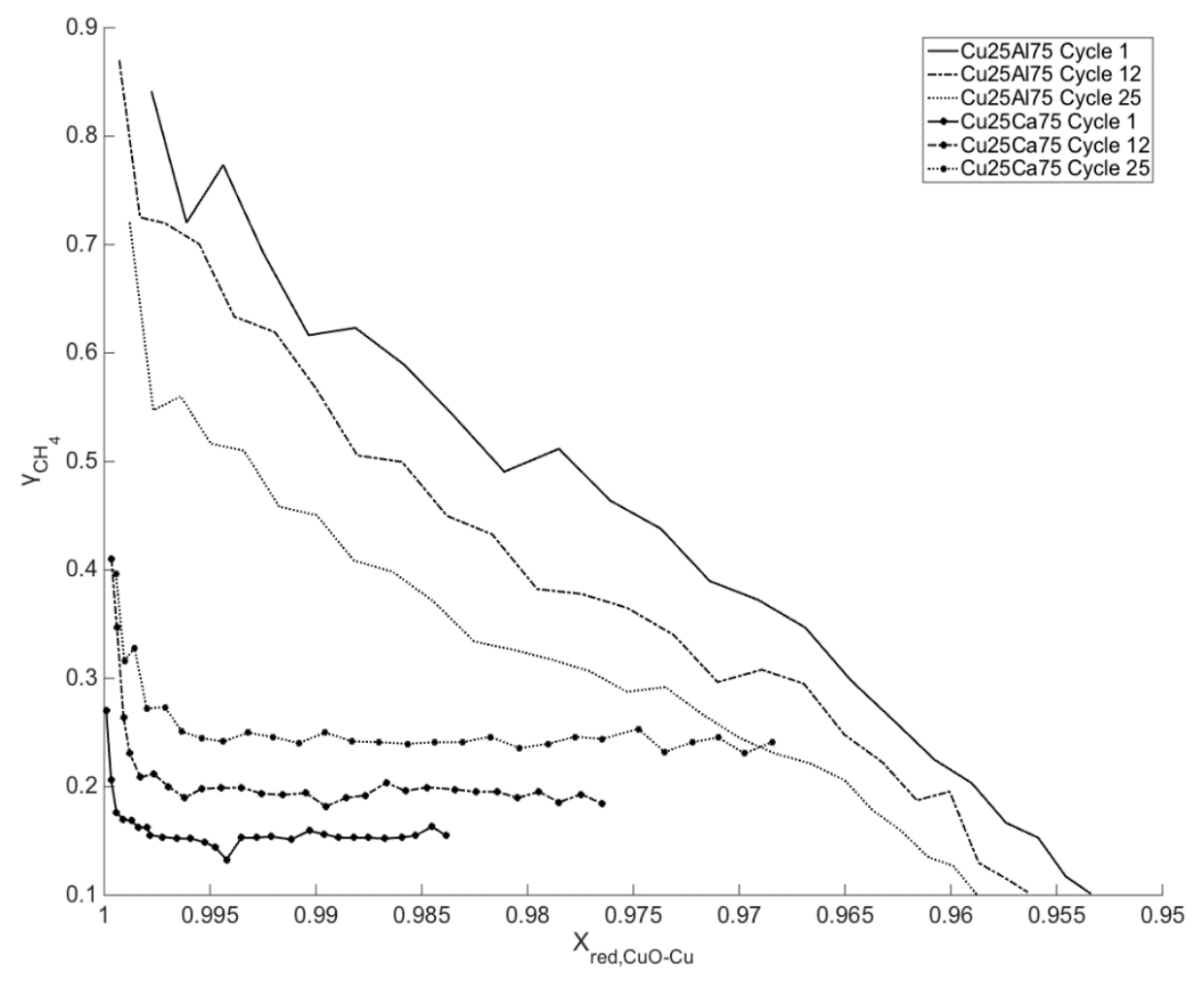

Figure 19: Redox cyclic behaviour of Cu25Al75 and Cu25Ca75 over 25 cycles assessed by oxygen carrier conversion vs. the conversion of $\mathrm{CH}_{4}$ to $\mathrm{CO}_{2}$

\section{Conclusions}

This series of experiments investigates the application of oxygen carriers for gaseous fuel conversion produced by the scalable pelletisation method utilising low-cost support materials. Copper (II) oxide in varying ratios was combined with either alumina-based cement, or $\mathrm{CaO}$ derived from limestone as support material in order to investigate the possible mechanical and chemical improvements. The oxygen carriers containing a greater ratio of support material are found to have enhanced crushing strength. Oxygen carriers comprised of a 1:3 ratio of support to active $\mathrm{CuO}$ showed increased crushing strength by a minimum of $280 \%$ compared to a pure pelletised $\mathrm{CuO}$. Elemental analysis shows the distribution of $\mathrm{CuO}$ and support material in an oxygen carrier particle was fairly uniform, but is highly dependent on the size ranges of the materials used in the production process.

In the fluidised bed investigations, all oxygen carriers exhibit a high $\mathrm{CO}$ conversion yield and are fully reducible from $\mathrm{CuO}$ to $\mathrm{Cu}$. In the $\mathrm{Al} 300$-supported oxygen carriers the initial redox cycle has the greatest fuel and oxygen carrier conversion. The general trend saw a decline in conversion as accumulating redox cycles are performed. In the $\mathrm{CaO}$-supported oxygen carriers, this trend is not observed except for $\mathrm{Cu} 75 \mathrm{Ca} 25$. This leads to the conclusion that the deactivation over increasing redox cycle numbers is more likely due to the deactivation of the $\mathrm{CuO}$ active material as well as its interaction with the Al300 support. All but one of the oxygen carriers suffered agglomeration, and the agglomeration was, as expected, more evident in carriers with higher ratios of $\mathrm{CuO}$. Oxygen carrier $\mathrm{Cu} 25 \mathrm{Al} 15$, which did not suffer 
from agglomeration, showed the greatest attrition, with a loss of approximately $8 \%$ of its initial mass through the 25-redox-cycle investigation. The reduction with methane produced a decreased reducibility of the oxygen carriers and gas conversion was limited to $15-25 \%$ and $50 \%$ for $\mathrm{Cu} 25 \mathrm{Ca} 75$ and $\mathrm{Cu} 25 \mathrm{~A} 175$, respectively. $\mathrm{Cu} 25 \mathrm{Ca} 75$ demonstrated improved conversion, where $\mathrm{Cu} 25 \mathrm{~A} 175$ experienced a decrease in conversion with increasing redox cycles, although its oxygen carrier and fuel conversion was consistently greater than that of $\mathrm{Cu} 25 \mathrm{Ca} 75$.

The pelletisation method used in this investigation is an extremely effective method for producing oxygen carrier materials, but its success strongly depends on the amount and type of materials used. The use of support material with $\mathrm{Cu}$-containing oxygen carriers is crucial to its potential long-term use in chemical looping. The investigation shows that Al300 support material offers a feasible option for further long-term stability testing when active $\mathrm{Cu}$ content is kept below $25 \%$. 


\section{Acknowledgments}

The experimental investigation was conducted in part at the Centre for CCS and Combustion at Cranfield University and the Department of Engineering at Cambridge University. The authors would like to acknowledge the following for their contributions in material supply in this research investigation. Gareth Williams (Johnson Matthey) for the supply of Copper (II) Oxide, Doris Van Garsel (Almatis GmbH) for the supply of Alphabond 300 and Liam Barkley (Longcliffe) for the supply of limestone. 


\section{References}

[1] A. Lyngfelt, B. Leckner, T. Mattisson, Chem. Eng. Sci. 56 (2001) 3101-3113.

[2] E. Jerndal, T. Mattisson, A. Lyngfelt, Chem. Eng. Res. Des. 84 (2006) 795-806.

[3] P. Moldenhauer, M. Rydén, T. Mattisson, A. Hoteit, A. Jamal, A. Lyngfelt, Energy and Fuels 28 (2014) 5978-5987.

[4] C. Linderholm, M. Schmitz, J. Environ. Chem. Eng. 4 (2016) 1029-1039.

[5] S.K. Haider, G. Azimi, L. Duan, E.J. Anthony, K. Patchigolla, J.E. Oakey, H. Leion, T. Mattisson, A. Lyngfelt, Appl. Energy 163 (2016) 41-50.

[6] J. Adánez, A. Abad, F. Garcia-Labiano, P. Gayan, L.F. de Diego, Prog. Energy Combust. Sci. 38 (2012) 215-282.

[7] A. Abad, J. Adánez, F. García-Labiano, L.F. de Diego, P. Gayán, J. Celaya, Chem. Eng. Sci. 62 (2007) 533-549.

[8] L.F. De Diego, F. García-Labiano, J. Adánez, P. Gayán, A. Abad, B.M. Corbella, J.M. Palacios, Fuel 83 (2004) 1749-1757.

[9] F. Donat, W. Hu, S.A. Scott, J.S. Dennis, Ind. Eng. Chem. Res. 54 (2015) 6713-6723.

[10] P. Gayán, I. Adánez-Rubio, A. Abad, L.F. De Diego, F. García-Labiano, J. Adánez, Fuel 96 (2012) 226-238.

[11] C.Y. Sim, T. Brown, Q. Chen, V. Sharifi, J. Swithenbank, J. Dennis, S. Scott, Chem. Eng. Sci. 69 (2012) 211-224.

[12] X. Zheng, L. Che, Y. Hao, Q. Su, J. Energy Chem. 25 (2016) 101-109.

[13] Q. Imtiaz, D. Hosseini, C. Müller, Energy Technol. 1 (2013) 633-647.

[14] H. Leion, T. Mattisson, A. Lyngfelt, Energy Procedia 1 (2009) 447-453.

[15] E.M. Eyring, G. Konya, J.S. Lighty, A.H. Sahir, A.F. Sarofim, K. Whitty, Oil Gas Sci. Technol. 66 (2011) 209-221.

[16] L. Duan, D. Godino, V. Manovic, F. Montagnaro, E.J. Anthony, Energy Technol. Submitted (2016).

[17] L.-S. Fan, Chemical Looping Systems for Fossil Energy Conversions, Wiley, 2010.

[18] M. Erans, T. Beisheim, V. Manovic, M. Jeremias, K. Patchigolla, H. Dieter, L. Duan, E. Anthony, Faraday Discuss. (2016).

[19] V. Manovic, Y. Wu, I. He, E.J. Anthony, Environ. Sci. Technol. 46 (2012) 12720-12725.

[20] P. Hallberg, D. Jing, M. Rydén, T. Mattisson, A. Lyngfelt, Energy \& Fuels 27 (2013) $1473-$ 1481 .

[21] C. Qin, J. Yin, B. Feng, J. Ran, L. Zhang, V. Manovic, Appl. Energy 164 (2016) 400-410.

[22] S. Penthor, F. Zerobin, K. Mayer, T. Pröll, H. Hofbauer, Appl. Energy 145 (2015) 52-59. 